Discussion Paper No. 08-031

Conditional Grants, Grant-Seeking and Welfare when there is Government Failure on the Subordinate Level

Ivo Bischoff

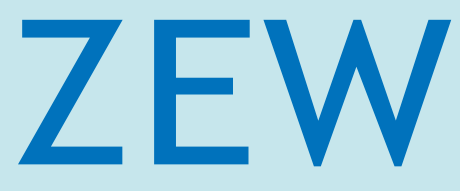

Zentrum für Europäische Wirtschaftsforschung $\mathrm{GmbH}$

Centre for European

Economic Research 
Discussion Paper No. 08-031

\title{
Conditional Grants, Grant-Seeking and Welfare when there is Government Failure on the Subordinate Level
}

\author{
Ivo Bischoff
}

Download this ZEW Discussion Paper from our ftp server:

ftp://ftp.zew.de/pub/zew-docs/dp/dp08031.pdf

Die Discussion Papers dienen einer möglichst schnellen Verbreitung von neueren Forschungsarbeiten des ZEW. Die Beiträge liegen in alleiniger Verantwortung der Autoren und stellen nicht notwendigerweise die Meinung des ZEW dar.

Discussion Papers are intended to make results of ZEW research promptly available to other economists in order to encourage discussion and suggestions for revisions. The authors are solely responsible for the contents which do not necessarily represent the opinion of the ZEW. 


\section{NON-TECHNICAL SUMMARY}

This paper addresses the welfare effects of conditional grants when there is government failure on the subordinate (hereafter regional) level. Government failure on the regional level may occur due to the influence of regional pressure groups and bureaucrats, poorly informed regional voters, lacking incentives to imitate superior solutions from other regions and ideological preference of regional governments. Regardless of the origin, government failure leads regional authorities to apply inadequate policy solutions in policy fields where they have the autonomy to choose between different solutions. In order to set incentives for the regions to apply (more) adequate solutions, the supra-ordinate government may not use orders. However, conditional grants distributed upon application may be an appropriate means. They initiate a competition for grants in which the regional authorities offer to apply superior policy solutions in order to attract conditional grants. On the other hand, substantial resources are used up for grant-seeking. This paper provides a theoretical model to assess the net effect on welfare. Increasing the share of conditional grants and lowering the share of potential recipients increases both changes in policy solutions and grant-seeking expenditures. We show that there is an optimal grant-distribution scheme that maximizes net welfare. It depends on the preferences of the regional authorities, the number of regions, the regional production function and the total funds available. When regional disparities in output are irrelevant, conditional grants are always efficiency-enhancing. The optimal share of conditional grants is higher the higher the potential gains while concentrating all means to a small number of regions is never optimal because it boosts grant-seeking effort. If interregional disparities matter, the welfare-maximizing share of conditional grants is much lower, in many cases even zero. At the same time, grants are optimally concentrated to a small number of regions. Welfare gains are larger when the central government can limit the social costs of grant-seeking through credible institutional arrangements (e.g. double-blind grant allocation procedures, application fees). In any case, conditional grants should be restricted to situations where a) the potential recipients are free in their choice of policy solutions and policy changes can only be achieved by appropriate incentives and b) the requirements to apply ex post performance based grants are not met. 


\section{ZUSAMMENFASSUNG}

Die vorliegende Arbeit befasst sich mit den Wohlfahrtseffekten von Zweckzuweisungen bei Staatsversagen auf der untergeordneten Ebene (hiernach Region). Dieses kann auf fehlende Innovationsanreize, auf den Einfluss von Interessenverbänden und Bürokraten, auf verzerrte Wählerpräferenzen oder auf ideologisch geprägte Parteipräferenzen zurückgehen. Unabhängig von der Ursache hat regionales Staatsversagen ineffiziente Politik-Lösungen in den Politikgebieten zur Folge, in denen die regionale Ebene über die Auswahl der Lösungen entscheidet. Zur Verringerung des Staatsversagens kann eine übergeordnete Institution in diesem Fall keine direkten Befehle anwenden, sondern sie muss Anreize setzen. Indem sie Zweckzuweisungen auslobt und auf Antrag vergibt, initiiert sie einen interregionalen Wettbewerb unter den potentiellen Empfängern. Diese werden die Anwendung verbesserten Politik-Lösungen anbieten, um ihre Chance of Zweckzuweisungen zu erhöhen. Diesem wohlfahrtssteigernden Effekt stehen allerdings Wohlfahrtsverluste durch regionales Grant-Seeking gegenüber. Das vorliegende Papier stellt ein theoretisches Modell vor, welches beide Effekte berücksichtigt. Generell gilt, dass eine Erhöhung des Anteils an Zweckzuweisungen und eine Verringerung der Anzahl potentieller Empfänger sowohl den Grant-seeking Aufwand als auch die Bereitschaft erhöht, bessere Politik-Lösungen anzuwenden. Wir zeigen, dass es ein optimales Zuweisungs-Verteilungssystem gibt, welches die Nettowohlfahrt maximiert. Es wird bestimmt durch die Präferenzen der regionalen Agenten, die Anzahl von Regionen, die regionale Produktionsfunktion sowie durch die Summe der insgesamt verfügbaren Mittel. Spielen interregionale Output-Disparitäten keine Rolle, so sind Zweckzuweisungen auf Antrag stets wohlfahrtssteigernd. Ihr optimaler Anteil an den gesamten Zuweisungen ist umso höher, je höher die potentiellen Wohlfahrtssteigerungen sind. Dabei ist es niemals optimal, die Mittel auf wenige Regionen zu konzentrieren. Sind regionale Disparitäten von Belang, so ist der optimale Anteil von Zweckzuweisungen deutlich niedriger, nicht selten liegt er bei 0. Zugleich ist eine strikte Konzentration der Mittel auf wenige Regionen optimal. Weitere Wohlfahrtsgewinne sind erreichbar, wenn die vergebende Regierung die sozialen Kosten des GrantSeeking durch glaubwürdige Institutionen begrenzen kann (insbes. doppelt-blinde Vergabeprozeduren, hohe Antragsgebühren). In jedem Fall ist die Verwendung von Zweckzuweisungen aber nur angebracht, wenn a) die potentiellen Empfänger die Politik-Lösungen autonom wählen können und somit verbesserte Lösungen nur durch Anreize induzierbar sind, und b) erfolgsabhängige ex post Zuweisungen nicht anwendbar sind. 


\title{
Conditional Grants, Grant-Seeking and Welfare when there is Government Failure on the Subordinate Level
}

\author{
Ivo Bischoff \\ Zentrum für Europäische Wirtschaftsforschung (ZEW), „Corporate Tax and Public Finance“ Research Unit, \\ L 7,1, D-68161 Mannheim, Germany \\ and \\ Department of Economics, University of Giessen, Licher Strasse 74, 35394 Giessen, Germany; \\ e-mail: ivo.bischoff@wirtschaft.uni-giessen.de,
}

\begin{abstract}
The paper addresses the welfare implications of conditional grants if government failure leads to inefficiencies in the production of regional public goods and services. Conditional grants may improve welfare by setting incentives for regions to improve efficiency. At the same time, resources are wasted in the process of grant-seeking. This paper provides a theoretical model to assess the net effect on welfare. A three-stage game-theoretic context is developed and simulations are performed to derive the optimal grant-distribution scheme. We found conditional grants to be welfare-enhancing in the vast majority of simulated scenarios under a classical utilitarian welfare function. Once distributional concerns are accounted for, the scope for conditional grants becomes limited.
\end{abstract}

Key words: conditional grants, government failure, rent-seeking, normative public finance JEL: D 7, H 77, H 5, H 11

The author would like to thank the participants of the ZEW-Kolloquium in May 2008 for helpful comments. 


\section{Introduction}

This paper wants to contribute to the literature on the political ecnonomy of intergovernmental grants. A number of authors provide evidence that supra-ordinate governments apply vertical grants to maximize political support (e.g., Grossman, 1994, 1996; Worthington and Dollery 1998). Especially the discretionary freedom in conditional grants is used to this end. The current paper focusses on the behavior of the recipients of grants on the subordinate level. Following Tullock (1980), conditional grants evoke wasteful grant-seeking among them. On the other hand, conditional grants may help to improve (productive) efficiency on the subordinate level. The efficiency-enhancing effect in the case of regional spillovers has been discussed in depth (e.g., Oates, 1999; Shah, 2006; Fenge and Wrede, 2007). This paper concentrates on inefficiencies that result from regional or local government failure (e.g., Chernick, 1979; Grossman and Mavros, 1999; Byrnes and Dollery, 2002; Oates, 2005) and the potential welfare-improvements inductible through conditional grants. Government failure on the sub-ordinate level can have a number of reasons. First, it may be attributed to the influence of pressure groups which press the regional or local authorities to apply inefficient solutions because these suit group members (e.g., Austen-Smith, 1997; Oates, 2005). Second, when the electorate does not punish the authorities for poor policy outcomes, these lack incentives to imitate superior policy solutions from other constituencies. Instead, they stick to overcome solutions (e.g., Oates, 1999; Belleflamme and Hindriks, 2005). Third, the electorate may be poorly informed and follow biased or false beliefs as to which policy solutions are most suitable. In order to win elections, parties offer popular yet inefficient solutions (e.g., Romer, 2003; Bischoff, 2008). Fourth, inefficient solutions may reflect the preferences of the bureaucracy in charge of providing the goods or services (e.g., Niskanen, 1971; Wintrobe 1997; Chang and Turnbull, 2002). Regardles of the underlying cause, government failure leads regional or local authorities to apply inedequate policy solutions. 
One obvious instrument to reduce government failure is performance based grants (e.g., Crain and O’Roark, 2004; Flynn, 2007). For some public tasks, however, suitable performance measures are missing or other requirements for applying performance based grants are not met. It may nevertheless be possible differentiate between policy solutions that promise preferential outcomes and those that yield poor results. This opens the opportunity for the supra-ordinate government to restrict conditional grants to those subordinate regions that apply relatively superior policy solutions. For this purpose, conditional grants are granted upon application. Therein, the subordinate authorities specify the policy solutions they intend to apply. Given the large number of applications, the sum of funds applied for regularly exceeds the means that the supra-ordinate government reserved for this purpose. Thus, some applications have to be turned down. It is precisely this competition that sets incentives for the subordinate authorities to improve efficiency in order to attract grants.

In this paper, we provide a model of this competition for grants that accounts for its welfare-enhancing effect as well as for the welfare losses due to grant-seeking. We argue that the net effect on welfare depends on the design of the grant-distribution scheme. The following section 2 presents the model and shows how the optimal grant-distribution scheme depends on the characteristics of the grantees, the number of sub-units, the production function and the total funds available. Section 3 presents three extensions to the model. The results and their implications are discussed in section 4. In particular, we sketch the preconditions for the applicability of conditional grants as a means to reduce government failure on the subordinate level. Section 5 concludes. 


\section{The model}

\subsection{Agents, production function and game structure}

Consider a federation consisting of $N$ regions. The regions are in charge of providing a certain public service $X$. The regional output depends on the resources used and the policy vector $A_{i}$. The latter describes the policy solution that the region $i$ applies in the production of $X$. Let the regional authorities in charge of regional production be risk-neutral and utility maximizing and let their utility function be given by the following expression:

$$
U=a\left(v_{i}-\lambda_{i}\right)-b\left(-\left(\overline{A_{i} A_{i}^{o}}\right)^{2}\right) \quad 0<a, b<1
$$

The utility is a positive function of the disposable budget $\left(v_{i}-\lambda_{i}\right)$ (e.g., Tullock, 1980; Wintrope, 1997). Here, $v_{i}$ stands for the sum of grants region $i$ receives while $\lambda_{i}$ is the amount of resources it devotes to the application for conditional funds. In addition, the regional government is assumed to have policy preferences. Let $A_{i}^{o}$ denote the regional government's bliss policy vector that maximizes regional utility when conditional grants are absent. One possible way to think of $A_{i}^{o}$ is to interpret it to be the policy vector which maximizes the support by regional interest groups. For example, $X_{i}$ may represent the quality of the public schooling in a region $i$ and the $A_{i}$ describes the mix of policy measures applied in this field (e.g., teaching methods, facility structure etc.). Here, the regional union of teachers, the parents' association or regional religious groups may try to exert an influence. In case voters do not punish the regional government for poor educational outcomes, $A_{i}^{o}$ may represent some previously applied yet overcome policy solution which is not changed because change is costly. Alternatively, the relevant regional electorate may entertain biased or false beliefs as to which are the most important skills, the most effective teaching methods or the best organisational struc- 
tures in education. In order to win the election, regional parties are forced to offer popular yet inefficient policy solutions. Finally, $A_{i}^{o}$ may be thought of to yield the highest procedural or ideological utility to the regional bureaucracy and politicians if pursued. The larger the distance between $A_{i}$ and $A_{i}^{o}\left(\overline{A_{i} A_{i}^{o}}\right)$, the lower regional utility - other things equal. The parameter $a$ captures the degree to which regional governments are budget-maximizing and $b$ captures the strength of their policy preferences.

Regions are assumed to be identical with respect to size, policy preferences, utility function and production function $X_{i}(\cdot)$.The higher $\left(v_{i}-\lambda_{i}\right)$, the higher $X_{i}-$ other things equal. At the same time, the output depends on the policy vector $A_{i}$ applied. Some policy vectors yield better results than others. Let $A^{\text {opt }}$ denote the policy solutions that maximizes $X_{i}$ for any given amount of $\left(v_{i}-\lambda_{i}\right)$. For reasons of simplicity, we hereafter assume that the elements of $A_{i}$ are linearly dependent and thus every policy vector can be represented by a scalar. The scalar might be interpreted to be the intensity with which a certain general policy principle or paradigm is followed. Thus, hereafter $A_{i}$ and $A_{i}^{o}$ and $A^{\text {opt }}$ are scalars. We assume $A_{i} \geq 0$ while $A^{\text {opt }}>>A_{i}{ }^{o}$. In the relevant interval for our analysis, let the output of the regional service $X_{i}$ be described by the following Cobb-Douglas-production function:

$$
X_{i}=\left(v_{i}-\lambda_{i}\right)^{q} \cdot\left(A_{i}\right)^{1-q} \quad 0 \leq q \leq 1
$$

It is based on the assumption that a region that receives conditional grants will apply $A_{i}$ task wide even when producing those parts of $X_{i}$ that are not financed by conditional grants. This assumption will be dropped in section 3.1. We furthermore assume that the regional production of $X$ is financed solely by earmarked vertical transfers from the central government. The latter has a fixed amount of funds $F$ to support the production of $X$. The parameter $f$ denotes the share of funds transferred in form of conditional grants distributed upon regional applica- 
tion (hereafter conditional grants). The remaining (1-f) fraction of $F$ is distributed as block grant of equal size to all $\mathrm{N}$ regions. Block grants are earmarked for the production of $X$ but distributed without prior application.

Now consider the situation of the central government that aims at maximizing the overall welfare $W F$. Let us assume that the government follows a simple utilitarian welfare function. Its objective is then to maximize overall output for a given $F=\bar{F}$. Given that regions are assumed to be identical, this in turn is equivalent to maximizing the average output:

$$
W F=\bar{X}=\frac{1}{N} \sum_{i=1}^{N} X_{i}
$$

If $f=0$, regions do not spent any resources on grant-seeking $\left(\lambda_{i}=0\right)$. They will use $v_{i}=F / N$ on the production of $X$ and apply $A_{i}^{o}$. For all values $f>0$, the probability that a certain region $i$ receives conditional grants is denoted by $p_{i}$. It depends on $\lambda_{i}$, on $A_{i}$ and on the corresponding $\lambda_{j}$ and $A_{j}$ of all other regions $j \neq i$. The more effort the region $i$ exerts in the process of applying for grants, the higher the probability of receiving them - other things equal. In addition, the probability is higher the more adequate $A_{i}$. Following Berry (1993), we assume that the process of grant-allocation can be modelled as if it was a random process in which $K<N$ regions receive a grant of size $F f / K$. Thus,

$$
v_{i}= \begin{cases}\frac{(1-f) F}{N}+\frac{f F}{K} & \text { in the case of successful grant-seeking } \\ \frac{(1-f) F}{N} & \text { else }\end{cases}
$$


The probability $p_{N}$ that region $i=N$ receives grants is given by the expression (Berry, 1993):

$p_{N}=\frac{\sum_{i=1}^{K-1} \pi_{i}+\pi_{N}+\sum_{i=2}^{K} \pi_{i}+\pi_{N} \ldots \sum_{i=N-K+1}^{N-1} \pi_{i}+\pi_{N}}{\sum_{i=1}^{K} \pi_{i}+\sum_{i=2}^{K+1} \pi_{i} \ldots \sum_{i=N-K+1}^{N} \pi_{i}}$

with $\pi_{i}=\pi\left(\lambda_{i}, G D F\left(\alpha_{i}\right)\right)$

and $\frac{\partial \pi_{i}}{\partial \lambda_{i}}>0 ; \frac{\partial \pi_{i}}{\partial G D F}>0$

In order to keep the Nash-equilibrium in grant-seeking tractable, we assume:

$$
\pi_{i}=\lambda_{i}\left(A_{i}-A_{i}^{o}\right)
$$

The central government does not give conditional grants to regions that stick to their bliss policy vectors $A_{i}^{o}$ or spend no resources on grant-seeking; that is hand in no application. Hereafter, let $\alpha_{i}=A_{i}-A_{i}^{o} . \alpha_{\mathrm{i}}$ represents the policy concessions of region i. The more concessions region is willing to make, i. e. the more it is willing to change its policy solution and approach $A^{\text {opt }}$, the higher $p_{i}$, other things equal. In addition, $p_{i}$ increases in $\lambda_{i}$.

The interaction of regional and central government can be modelled as a sequential game consisting of three stages: In stage 1 , the central government sets $f$ and $K$. In stage 2 , the regional governments apply for conditional grants. In order to receive grants, they offer a policy vector $A_{i} \neq A_{i}^{o}$ and spend scarce resources on grant-seeking. Both $A_{i}$ and the grant-seeking effort $\lambda_{i}$ depend on $f$ and $K$. In stage 3 , the funds are distributed and regions use these funds net of grant-seeking expenditures to produce $X$. We assume that there are no information asymmetries between regional and central government. In order not to destroy the chance to 
receive conditional grants in the future, regions receiving conditional grants will apply the policy vector $A_{i}$ offered in their application. Regions that were not successful apply $A_{i}^{o}$. In search for the welfare-maximum, the central government has to solve this game by backward induction. For this purpose, it is necessary to develop the region's reaction functions to $f$ and $K A_{i}=A_{i}\left(f, K, A_{i}^{o}\right)$ respectively $\lambda_{i}=\lambda_{i}\left(f, K, A_{i}^{o}\right)$ and to establish the expression for the corresponding output $X_{i}$. Given these reaction functions, the maximization task of the central government reads as follows:

$$
\{f, K\}=\underset{\{f, K\}}{\arg \max } W F
$$

\subsection{Regional grant-seeking and the optimal grant-distribution scheme}

Given that all regions are identical, we assume that $\pi_{i}=\pi_{j} \forall i, j$ holds in the Nashequilibrium: Thus, the expected change in $\mathrm{p}_{\mathrm{i}}$ from an incremental change in $\lambda_{i}$ respectively $\alpha_{i}$ in the Nash-equilibrium is given by the following expressions (Berry, 1993):

$$
\begin{aligned}
& \frac{\partial p_{i}}{\partial \lambda_{i}}=\frac{\partial \pi_{i}}{\partial \lambda_{i}} \frac{(N-K)}{N^{2} \pi_{i}}=\frac{(N-K)}{N^{2} \lambda_{i}} \\
& \frac{\partial p_{i}}{\partial \alpha_{i}}=\frac{\partial \pi_{i}}{\partial \alpha_{i}} \frac{(N-K)}{N^{2} \pi_{i}}=\frac{(N-K)}{N^{2} \alpha_{i}}
\end{aligned}
$$

To save notation, we will hereafter drop the subindex $i$ to denote the single region. From the point of view of the representative region, the maximization problem is the following:

$$
\begin{array}{cl}
\operatorname{Max} & U=U(v, \alpha) \\
\text { s.t. } & \lambda \leq v \\
& \lambda, \alpha \geq 0
\end{array}
$$

For those cases where $f>0$, their expected utility is given by: 


$$
E[U]=\frac{K}{N}\left(a\left(\frac{(1-f) F}{N}+\frac{f F}{K}-\lambda\right)+b\left(-(\alpha)^{2}\right)\right)+\left(\frac{N-K}{N}\right) a\left(\frac{(1-f) F}{N}-\lambda\right)
$$

We apply a Kuhn-Tucker approach to solve the maximization problem of the representative government (e.g., Hoy et al., 2001:67pp.). The corresponding Lagrange-function reads:

$$
Z=E[U]+\mu(v-\lambda)
$$

The first-order conditions for a maximum in utility are given by:

$$
\begin{aligned}
& \frac{\partial Z}{\partial \lambda}=-a+a \frac{\partial p}{\partial \lambda}\left(\frac{f F}{K}\right)-b \frac{\partial p}{\partial \lambda} \alpha^{2}-\mu \leq 0 \quad \lambda \geq 0 \quad \text { and } \quad \lambda \frac{\partial Z}{\partial \lambda}=0 \\
& \frac{\partial Z}{\partial \alpha}=\frac{\partial p}{\partial \alpha} a \frac{f F}{K}-\frac{\partial p}{\partial \alpha} b \alpha^{2}-2 p b \alpha \leq 0 \quad \alpha \geq 0 \quad \text { and } \quad \alpha \frac{\partial Z}{\partial \alpha}=0 \\
& \frac{\partial Z}{\partial \mu}=v-\lambda \geq 0 \quad \mu \geq 0 \quad \text { and } \quad \mu \frac{\partial Z}{\partial \mu}=0
\end{aligned}
$$

From expression (12b), we can derive the optimal policy concession $\alpha^{*}$ :

$$
\alpha^{*}=\sqrt{\frac{a}{b} \frac{f F}{K} \frac{(N-K)}{(N-K)+2 K N}}
$$

Ruling out the negative square-root as implausible, it is easy to see that $\alpha^{*}>0$ as soon as $f>0$ and - which is implied by the first condition $-K<N$. The larger $a / b$, i. e. the larger the relative weight of budget-maximizing in the regional government's utility function, the larger $\alpha^{*}$. At the same time, $\alpha^{*}$ increases in $f(\partial \lambda * / \partial f>0)$ and decreases in $K\left(\Delta \alpha^{*} / \Delta K<0\right)$.

In a next step, the optimal grant-seeking effort $\lambda^{*}$ is derived from expression (12a). Assuming the restriction in (12c) to hold, we arrive at the following internal solution: 


$$
\lambda^{*}=\frac{N-K}{N^{2}}\left[\frac{f F}{K}-\frac{b}{a} \alpha^{2}\right]=\frac{N-K}{N^{2}} \frac{f F}{K}\left[1-\frac{(N-K)}{(N-K)+2 K N}\right]
$$

We can infer a strictly positive grant-seeking effort as soon as conditional grants are available (i.e. $f>0 ; K<N)$. The restriction in (12c) is satisfied if the following inequality holds:

$$
f \leq\left(1+\frac{N-K}{N K}\left[1-\frac{(N-K)}{(N-K)+2 K N}\right]\right)^{-1}
$$

Figure 1 shows the critical values of $f$ as a function of $K$ and for two different values of $N$ ( $N=24, N=100)$. In the most restrictive case where $K=1$, the corner-solution applies for values of $f>0.6$. As $K$ increases, the corner-solution only applies to cases where almost all central funds are distributed via conditional grants. Restriction (15) becomes less restrictive as $\mathrm{N}$ increases. ${ }^{1}$ In those cases where it does apply, the grant-seeking effort is given by the limit $\lambda=(1-f) F / N$

Where this restriction applies, the regional government faces incentives to set $f$ very large to change the policy vector and at the same time limits the grants-seeking effort due to the restriction (15). Taking this argument to the limit, it will set a value of $f$ just below 1 . While this strategy is possible within the narrow world of the model presented here, it is unlikely to work in the real world because of the possibility to cross-subsidize grant-seeking by reducing expenditures on other public services. Incorporating this possibility in the current model would require a number of additional ad hoc assumptions. As we will show below, restriction (15) holds for virtually all realisations of the current model. The restriction applies only to cases with extreme parameter settings, e.g. for $a \approx 1$. For these cases, we will hereafter assume that the central government will set $f$ and $K$ to the welfare-maximizing internal solution. The assumption can be justified by the fact that in those cases where restriction (15) applies, regions that do not receive grants witness $X_{i}=0$ because they have no resources to spend on the program itself. 
Figure 1: Critical values of $f$ as a function of $K(N=24 ; N=100)$

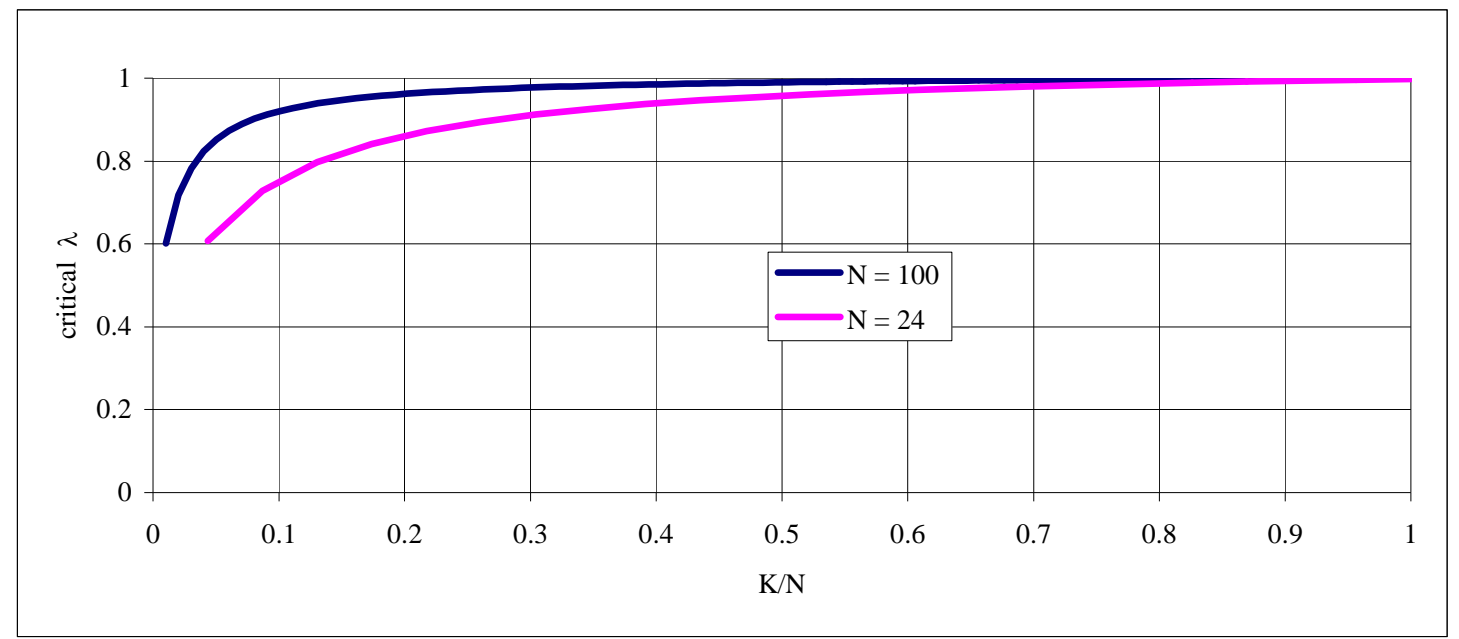

Figure 2: Critical values for which $\Delta \lambda * / \Delta K>\mathbf{0}$ (highest value of $K$ )

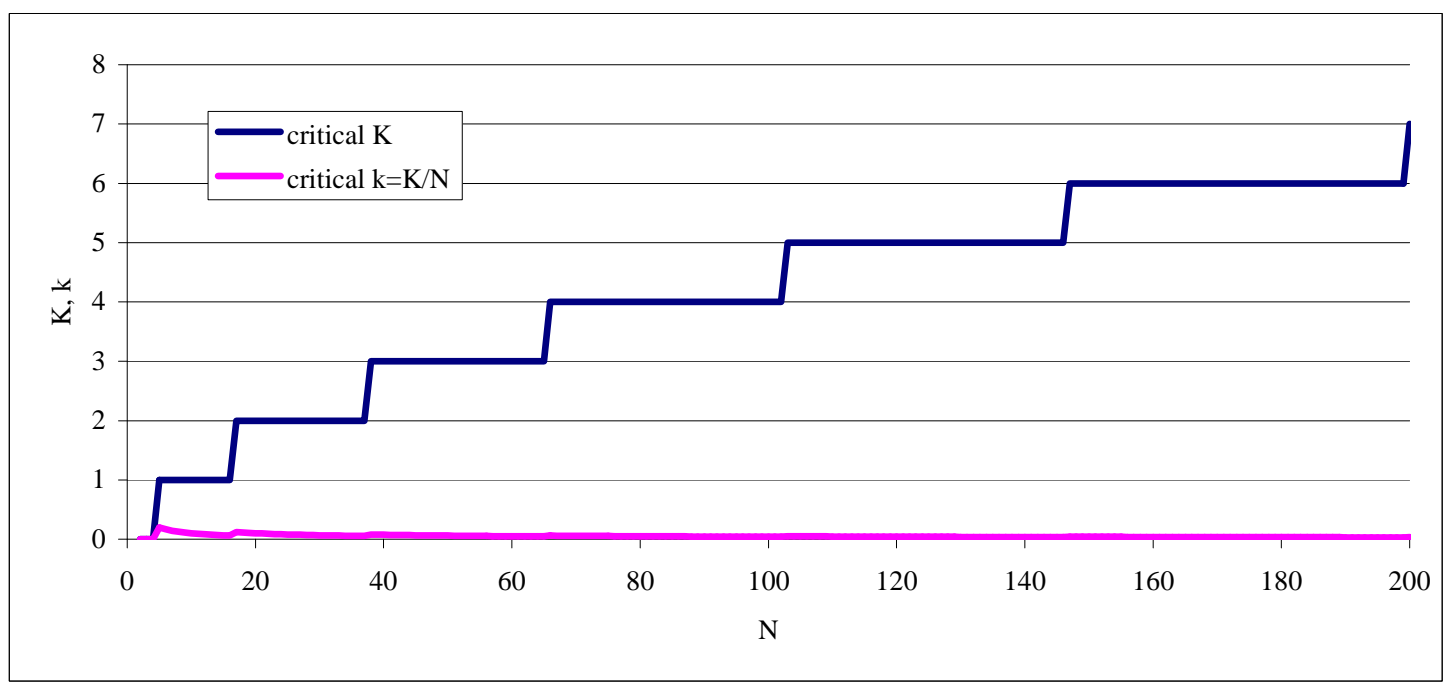

As long as restriction (15) holds, $\lambda^{*}$ increases in $f(\partial \lambda * / \partial f>0)$ but is independent of $a$ and $b$. For all situations where $N>4$, the sign of $\Delta \lambda * / \Delta K$ changes from positive to negative as $K$ increases, for $N \leq 4, \Delta \lambda * / \Delta K<0$ for all values of $K$. In general, positive signs can only be expected if the ratio $K / N$ is small. For all values of $K$ below the critical value depicted by the line in figure 2, $\Delta \lambda * / \Delta K>0$ (for values of $N \leq 200$ ). 
In sum, the Nash-equilibrium among regions derived here reveals an essential trade-off: Increasing the share of conditional grants improves overall welfare by causing the $K$ regions that receive conditional grants to apply a more appropriate policy vector. At the same time, a concomitant increase in grant-seeking effort reduces welfare in all regions $(\partial \lambda * / \partial f>0)$. A similar trade-off exists when the central government changes $K$ because both $\alpha^{*}$ and $\lambda^{*}$ decrease in $K$ for the vast majority of cases. The net effect of changes in $f$ and $K$ on welfare thus depends on the production function for $X$.

The central government aims at maximizing the expected output of the representative region:

$$
E[X]=\frac{K}{N}\left(\frac{(1-f) F}{N}+\frac{f F}{K}-\lambda\right)^{q}\left(\alpha+A_{i}^{o}\right)^{1-q}+\left(\frac{N-K}{N}\right)\left(\frac{(1-f) F}{N}-\lambda\right)^{q}\left(A_{i}^{o}\right)^{1-q}
$$

Its maximization problem thus reads:

$$
\begin{aligned}
\operatorname{Max} & W F=X\left(v, \lambda^{*}, A_{i}^{o}+\alpha^{*}\right) \\
\text { s.t. } & 0<K<N \\
& 0 \leq f \leq 1 \\
& \lambda^{*}=\lambda(f, K) \\
& \alpha^{*}=\alpha(f, K) \\
& v=v(f, K)
\end{aligned}
$$

Due to the fact that $K$ is an integer, we cannot apply a conventional Kuhn-Tucker approach to solve this problem. ${ }^{2}$ More importantly, we cannot derive general expressions for the welfare maximizing combination of $f$ and $K$ (hereafter $\left(f^{*}, K^{*}\right)$ ) and use these expressions to show ana- 
lytically how $\left(f^{*}, K^{*}\right)$ depends on the exogenous parameters $a, b, A_{i}^{o}, q, \bar{F}$, and $N$. Instead, simulations are used to derive the combination of $K$ and $f$ that - given the regional reaction to these parametersand the restrictions on $K$ and $f$-maximizes $W F$. In these simulations, we derive $\left(f^{*}, K^{*}\right)$ for a specific parameter constellation and show how it changes if we vary parameters systematically. Table 1 shows the parameter values in the standard scenario.

Table 1: Exogenous parameters in the standard simulation scenario

\begin{tabular}{|l|c|c|c|c|c|}
\hline Parameter & $A_{i}^{o}$ & $\begin{array}{c}a \\
(b=1-a)\end{array}$ & $N$ & $\bar{F}$ & $q$ \\
\hline Standard value & 0.2 & 0.5 & 24 & $\mathrm{~N}$ & 0.5 \\
\hline
\end{tabular}

In the standard scenario, simulations yield an optimal strategy of the central government $\left(f^{*}, K^{*}\right)=(0.52,9)$ and the corresponding average program output is given by $X^{*}=0.514$. Compared to the output of $X_{0}=0.447$ that would emerge without conditional transfers (i. e. for $f=0$ ), an optimally designed conditional transfer scheme can increase net welfare by $14.9 \%$. The regional grant-seeking effort amounts to $\lambda^{*}=0.035$ and the change in the policy vector is given by $\alpha^{*}=0.216$. The $\mathrm{K}$ regions that received conditional grants use resources equal to $v-\lambda^{*}=0.48+1.387-0.035=1.82$, the remaining $N$ - $K$ regions use $v-\lambda^{*}=0.445$. Their output is given by $X_{K}=0.870$ respectively $X_{N-K}=0.298$ (see table 2, appendix). 
Figure 3: Simulation results for the variations in $a$ for task-wide concessions
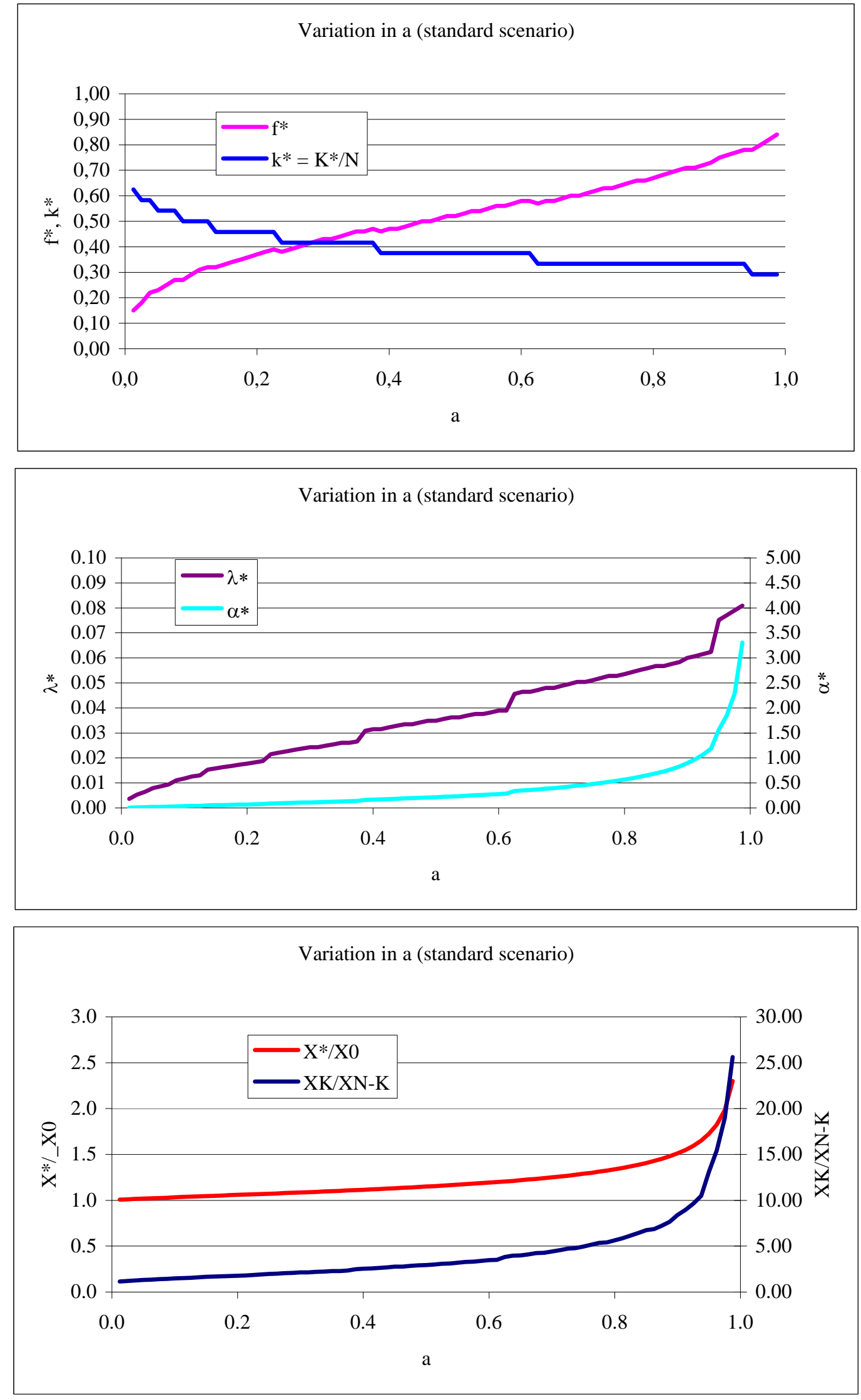


\subsection{Simulating variations in exogenous parameters}

Starting from this standard scenario, we describe series of simulations to analyse the impact of different values for the exogenous parameters. First, we will turn to the relative weights of budget maximization in the regional utility function. The larger the corresponding parameter $a$, the larger the utility the regional government derives from the amount of disposable budgetary means relative to the losses in utility they witness when deviating from $A_{i}^{o}$. For any given scheme $(f, K), \alpha^{*}$ and $\lambda^{*}$ increase in a. Our simulations show that the larger $a$ is, the larger $f^{*}$, the smaller $K^{*}$ and the larger the ratio of $X^{*} / X_{0}$ (see figure 3). The same basic pattern shows if we use other values of $q, A_{i}^{o}$ or $N$ (see table 2) instead of the standard values. For $q=0.75$ and $A_{i}^{o}=0.5$, the opportunity costs of grant-seeking are larger and the gains from policy vector changes are smaller. For this reason, $f^{*}$ is smaller than in the standard scenario while $K^{*}$ is larger. The opposite is true when $q=0.25$ or $A_{i}^{o}=0.1$.

The higher $A_{i}^{o}$, the less severe the regional government failure, the larger $X_{0}$ and the higher are opportunity costs of grant-seeking. Consequently, $f^{*}$ decreases and $K^{*}$ increases in $A_{i}^{o}$, leading to a reduction in $\alpha^{*}$ and $\lambda^{*}$. The opportunity costs of grant-seeking increase in $q$ while the benefits from changes in the policy vector decrease. Thus $f^{*}$ decreases while $K^{*}$ increases in $q$. As a result, $\alpha^{*}$ and $\lambda^{*}$ are reduced. In simulations where $N$ and $\bar{F}$ increase simultaneously such that $\bar{F} / N=1, f^{*}$ decreases in $\mathrm{N}$ as does the share of regions that receive conditional grants $k^{*}=K^{*} / N$. This causes $\alpha^{*}$ and $\lambda^{*}$ to increase. From expression (14) and (15), it is easy to see that both $\alpha^{*}$ and the grant-seeking effort $\lambda^{*}$ increase with the amount of

funds available $\bar{F} / N$ per region. From the perspective of the central government, the welfare-improving responsiveness of $\alpha^{*}$ is initially larger than the welfare-losses to increased 
grant-seeking. As a consequence, $f^{*}$ increases in $\bar{F} / N$ while the optimal number of recipients $K^{*}$ reduces only marginally.

In a next step, we randomly generate 5000 possible parameter constellations and calculated the correlation matrix between these parameters on the one and $f^{*}$ and $k^{*}$ respectively $\alpha^{*}$ and $\lambda^{*}$ on the other (see table 3 , appendix). The purpose of this analysis is to see whether the relationship between the endogenous variables, in particular $\left(f^{*}, k^{*}\right)$ and the exogenous parameters that we derived above remain valid when more than one exogenous parameter changes. These results are affirmative. The optimal values $f^{*}$ and $k^{*}$ are negatively correlated. Schemes with a high $f^{*} / k^{*}$ ratio are found in those cases where the efficiency gain from conditional grants $\left(X^{*} / X_{0}\right)$ is large. As natural side-effects, these high-ratio schemes go along with high values for $\alpha^{*}$ and $\lambda^{*}$ and a large ratio of $X_{K} / X_{N-K}$.

\section{Extensions}

\subsection{Project-specific concessions}

So far, we assumed that - regardless of the share of conditional grants $f$ - these grants make the successful $K$ regional government apply the superior policy vector $A_{i}$ in all the activities that involve the production of $X$, that is concessions are made task-wide. In many cases, conditional grants are offered to support the regions in clearly defined projects and the regional applications describe only these projects and the policy solutions therein. In these cases, it is reasonable to assume that the policy concessions $\alpha$ are restricted to the specific project that is financed through the conditional grants whereas the regional government continues to apply $A_{i}{ }^{o}$ in the other activities funded by the block grant. To capture this effect, the utility function has to be changed because the utility losses due to deviations from $A_{i}^{o}$ only 
apply to a fraction of their activities. The simplest way to do this is by scaling the relevant utility losses with the size of this fraction:

$$
U^{\prime}=a\left(v_{i}-\lambda_{i}\right)-\left(\frac{f N}{K+f(N-K)}\right) b\left(-\left(\overline{A_{i} A_{i}^{o}}\right)^{2}\right) \quad 0<a, b<1
$$

This leads to changes in the first order conditions for a utility maximum on the regional level and to changes in $\alpha^{*}$. The new equilibrium value $\alpha^{*}$ for the optimal concession is given by:

$$
\alpha^{* \prime}=\sqrt{\frac{a}{b} \frac{F(K+f(N-K))}{K N} \frac{(N-K)}{(N-K)+2 K N}}
$$

For any $(f, K), \alpha^{*}$ ' is larger than $\alpha^{*}$. Their ratio increases in $K / N$ and decreases in $f$ :

$$
\frac{\alpha^{* \prime}}{\alpha^{*}}=\sqrt{1+\frac{K(1-f)}{f N}}
$$

For the grant-seeking effort, the expression for the equilibrium remains unchanged, i.e. $\lambda^{*}=\lambda^{*}$ (see expression (14)). In other words, the regional authorities are more responsive to conditional grants in their policy concessions but not in their grant-seeking expenditures. At the same time, the overall increase in output from a given concession $\alpha$ is lower than under task-wide concessions. Given the functional form of $X_{i}(\cdot)$, the necessary changes are not trivial. For reasons of simplicity, we use the following modified expected output of the representative region:

$$
\begin{gathered}
E[X]=\frac{K}{N}\left(\frac{(1-f) F}{N}+\frac{f F}{K}-\lambda\right)^{q}\left(\left(\frac{f N}{K+f(N-K)}\right) \alpha+A_{i}^{o}\right)^{1-q} \\
+\left(1-\frac{K}{N}\right)\left(\frac{(1-f) F}{N}-\lambda\right)^{q}\left(A_{i}^{o}\right)^{1-q}
\end{gathered}
$$


Figure 4: Simulation results for variations in $a$ for project-specific concessions
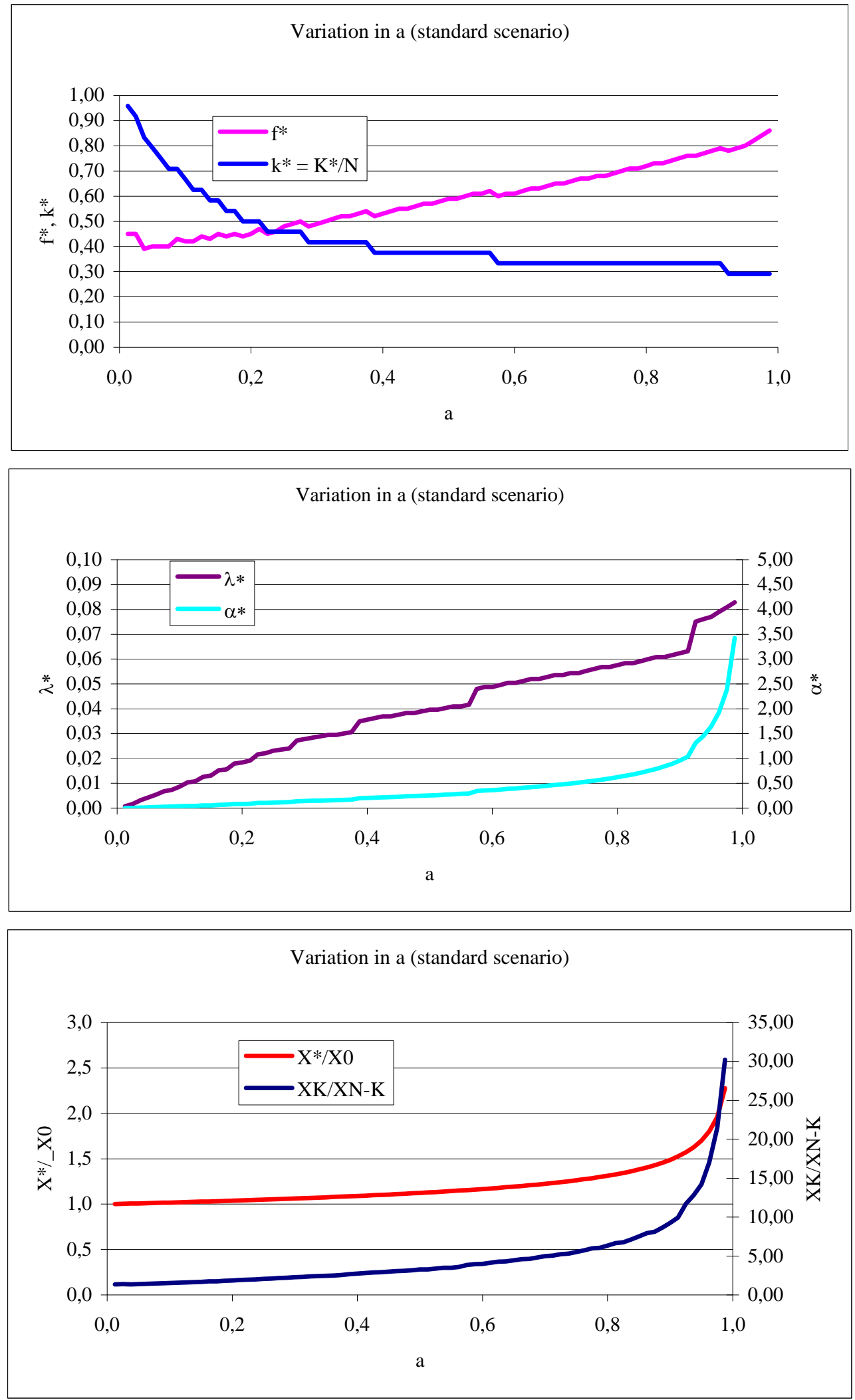
Expression (16') implies that the output can be modelled as if the region applied a policy vector $A_{i}$ ' that is a weighed average of $A_{i}^{o}$ and $A_{i}=\alpha+A_{i}^{o}$ with the weight being region $i$ 's share of conditional grants in gross funds. The optimization problem in expression (17) remains valid here.

We reran the simulations from section 2.3 to generate the optimal grant-distribution scheme assuming project-specific concessions (see figure 4 and table 4 ; appendix). While $f^{*}$, $\alpha^{*}$ and the resulting ratios of $X^{*} / X_{0}$ and $X_{k} / X_{N-K}$ are generally higher than under task-wide concessions, the other variables show only minor changes. The general pattern of results is not changed. The same holds for other scenarios and for the simulations involving multiple parameter variations. ${ }^{3}$

\subsection{Distributional concerns}

One important side-effect of grant-distribution is the inequality in output between regions that receive conditional grants and regions that do not. The ratio of $X_{K} / X_{N-K}$ is a positive function of the welfare gains that can be achieved through conditional grants $X^{*} / X_{0}$ ( $\rho=0.788$ for task-wide concessions; see table 3). The simplest way to account for distributional concerns is by using the following modified utilitarian welfare function:

$$
W F=K X_{K}+\phi(N-K) X_{N-K} \quad \text { with } \phi \geq 1
$$

The parameter $\phi$ gives the output in those regions that do not receive conditional grants a higher weight in the welfare function. 
We reran the major simulations in section 2.3 and 3.1 using this modified welfare function (see table 5 and 6, appendix). As can be expected, $f^{*}$ is a negative function of $\phi$. An important difference emerges with respect to the optimal grant-distribution scheme $\left(f^{*}, k^{*}\right)$ : While corner-solutions were not observed under the standard utilitarian welfare function, they are quite frequent here. Table 7 reports on the number of corner-solutions and $\left(f^{*}, k^{*}\right)$ under the 5000 simulations using randomly chosen parameter constellations.

Table 7: Distribution of $\left(f^{*}, k^{*}\right)$ for 5000 randomly chosen parameter constellations

\begin{tabular}{|l|c|c|c|c|c|c|}
\hline \multirow{2}{*}{} & \multicolumn{2}{|c|}{ Task-wide concessions } & \multicolumn{2}{c|}{ Project-specific concessions } \\
\cline { 2 - 7 } & $\phi=1$ & $\phi=1.1$ & $\phi=1.2$ & $\phi=1$ & $\phi=1.1$ & $\phi=1.2$ \\
\hline Corner solutions $f^{*}, k^{*}=0$ & $0.0 \%$ & $14.2 \%$ & $26,6 \%$ & $0.0 \%$ & $52.1 \%$ & $56.7 \%$ \\
\hline Solutions with $f^{*}<10 \%$ & $5.5 \%$ & $79.4 \%$ & $86.3 \%$ & $0.0 \%$ & $81.9 \%$ & $87.5 \%$ \\
\hline Solutions with $f^{*}<50 \%$ & $91.5 \%$ & $95.5 \%$ & $97.3 \%$ & $84.9 \%$ & $94.9 \%$ & $96.9 \%$ \\
\hline Average $f^{*}$ & & & & & \\
\hline Solutions with $k^{*}<10 \%$ & $4.3 \%$ & $85.4 \%$ & $93.4 \%$ & $5.0 \%$ & $90.7 \%$ & $95.6 \%$ \\
\hline Solutions with $k^{*}<50 \%$ & $56.2 \%$ & $100 \%$ & $100 \%$ & $30.1 \%$ & $100 \%$ & $100 \%$ \\
\hline
\end{tabular}

Boundaries: $0.15 \leq \mathrm{a} \leq 0.85,0.15 \leq \mathrm{q} \leq 0.85 ; 0.1 \leq A_{i}^{o} \leq 2 ; \quad 2 ; 1 \leq \bar{F} / N \leq 2 ; 12 \leq \mathrm{N} \leq 132$.

For $\phi=1.2$, corner solutions occur in approximately $25 \%$ of the cases with random multiple parameter variations for task-wide concessions and in more than $50 \%$ for projectspecific concessions. In those cases when $f^{*}>0, f^{*}$ and $k^{*}$ is found to be substantially lower than under the standard welfare function. As a result of this strategy, the interregional inequal- 
ity in funds is smaller and so is the ratio $X_{K} / X_{N-K}$. Finally, we ran logit-regressions to explain the occurrence of corner solutions if $\phi>1$ (see table 8). Accordingly, corner solutions are more likely the lower $a$ and larger $N, q, \bar{F}, A_{i}{ }^{\circ}$ and $\phi$.

Table 8: Logit-regression for 5000 randomly chosen parameter constellations dependent variable: $P\left(\right.$ corner solution for $\left.\left(f^{*}, k^{*}\right)\right)$

\begin{tabular}{|c|c|c|c|c|c|c|c|}
\hline & \multicolumn{3}{|c|}{ Task-wide concessions } & \multicolumn{3}{|c|}{ Project specific concessions } & \multirow{2}{*}{$\begin{array}{l}\text { All with } \\
\text { var. } \phi\end{array}$} \\
\hline & $\phi=1.1$ & $\phi=1.2$ & $1 \leq \phi \leq 1.2$ & $\phi=1.1$ & $\phi=1.2$ & $1 \leq \phi \leq 1.2$ & \\
\hline Intercept & $\begin{array}{c}-10.72 * * * \\
(0.5355)\end{array}$ & $\begin{array}{c}-10.86^{* * *} \\
(0.414)\end{array}$ & $\begin{array}{c}-56.64 * * * \\
(2.686)\end{array}$ & $\begin{array}{c}-11.76^{* * *} \\
(0.480)\end{array}$ & $\begin{array}{c}-14.64 * * * \\
(0.585)\end{array}$ & $\begin{array}{c}-38.27 * * * \\
(1.635)\end{array}$ & $\begin{array}{c}-46.43^{* * *} \\
(1.401)\end{array}$ \\
\hline$N$ & $\begin{array}{c}0.070 * * * \\
(0.005)\end{array}$ & $\begin{array}{c}0.071^{* * *} \\
(0.004)\end{array}$ & $\begin{array}{c}0.65 * * * \\
(0.005)\end{array}$ & $\begin{array}{c}0.050 * * * \\
(0.005)\end{array}$ & $\begin{array}{c}0.076^{* * *} \\
(0.005)\end{array}$ & $\begin{array}{c}0.041^{* * *} \\
(0.004)\end{array}$ & $\begin{array}{c}0.047 * * * \\
(0.003)\end{array}$ \\
\hline$q$ & $\begin{array}{l}8.01^{* * *} \\
(0.461)\end{array}$ & $\begin{array}{l}7.09 * * * \\
(0.344)\end{array}$ & $\begin{array}{l}7.75^{* * *} \\
(0.475)\end{array}$ & $\begin{array}{c}13.08 * * * \\
(0.539)\end{array}$ & $\begin{array}{c}15.29 * * * \\
(0.627)\end{array}$ & $\begin{array}{c}10.90 * * * \\
(0.441)\end{array}$ & $\begin{array}{c}9.23 * * * \\
(0.308)\end{array}$ \\
\hline $\bar{F}$ & $\begin{array}{c}-0.046 * * * \\
(0.003)\end{array}$ & $\begin{array}{c}-0.032 * * * \\
(0.002)\end{array}$ & $\begin{array}{c}0.034 * * * \\
(0.002)\end{array}$ & $\begin{array}{c}-0.031 * * * \\
(0.002)\end{array}$ & $\begin{array}{c}-0.031 * * * \\
(0.003)\end{array}$ & $\begin{array}{c}-0.026 * * * \\
(0.003)\end{array}$ & $\begin{array}{c}-0.028 * * * \\
(0.002)\end{array}$ \\
\hline$a$ & $\begin{array}{c}-13.56 * * * \\
(0.620)\end{array}$ & $\begin{array}{c}-8.65 * * * \\
(0.370)\end{array}$ & $\begin{array}{c}-11.08 * * * \\
(0.565)\end{array}$ & $\begin{array}{c}-9.73 * * * \\
(0.457)\end{array}$ & $\begin{array}{c}-9.14^{* * *} \\
(0.455)\end{array}$ & $\begin{array}{c}-8.38 * * * \\
(0.383)\end{array}$ & $\begin{array}{c}-8.84 * * * \\
(0.299)\end{array}$ \\
\hline$A_{i}{ }^{0}$ & $\begin{array}{l}\text { 7.06*** } \\
(0.306)\end{array}$ & $\begin{array}{l}6.46^{* * *} \\
(0.219)\end{array}$ & $\begin{array}{c}7.081^{* * *} \\
(0.325)\end{array}$ & $\begin{array}{c}9.73^{* * *} \\
(0.340)\end{array}$ & $\begin{array}{c}10.21^{* * *} \\
(0.367)\end{array}$ & $\begin{array}{c}25.68 * * * \\
(1.263)\end{array}$ & $\begin{array}{c}7.32 * * * \\
(0.189)\end{array}$ \\
\hline$\phi$ & & & & & & & $\begin{array}{c}29.06 * * * \\
(1.020)\end{array}$ \\
\hline $\begin{array}{l}\text { project- } \\
\text { specificity }\end{array}$ & & & & & & & $\begin{array}{l}5.90 * * * \\
(0.1611)\end{array}$ \\
\hline $\begin{array}{l}\text { Likelihood- } \\
\text { ratio }\end{array}$ & $2688 * * *$ & $3589 * * *$ & $6149 * * *$ & $5192 * * *$ & $5231 * * *$ & $4859 * * *$ & $8747 * * *$ \\
\hline \# obs. & 5.000 & 5.000 & 5.000 & 5.000 & 5.000 & 5.000 & 10.000 \\
\hline Pseudo- $\mathrm{R}^{2}$ & 0.658 & 0.620 & 0.826 & 0.750 & 0.765 & 0.702 & 0.7119 \\
\hline
\end{tabular}

(Standard error in parentheses); *** significant at the $1 \%$ level.

\subsection{Upper limits to the grant-seeking effort}

In the previous sections, high values of $f$ and low values of $k$ lead to higher concessions but also to more grant-seeking. Especially under the classical utilitarian welfare function, the optimal grant-distribution scheme is defined by moderate values for both parameters. If the 
central could effectively limit grant-seeking to a certain level $\lambda^{\max }$, welfare may be increased. The advantage would be twofold. First, for the current optimal combinations $\left(f^{*}, k^{*}\right)$, the grant-seeking effort would be lower whenever $\lambda^{*}>\lambda^{\max }$. Second and more importantly, other grant-distribution schemes with higher $f$ and lower $k$ may become feasible. This section points at the potential welfare gains from an upper limit to $\lambda=\lambda^{\max }$. All other assumptions of the previous sections remain unchanged.

As long as $\lambda \leq \lambda^{\max }$, the solutions described in the previous sections apply. For situations where the optimal grant-seeking effort according to expression (14) exceeds $\lambda^{\max }$, regions cannot increase $p_{i}$ through additional grant-seeking but only through additional policy concessions. It can be shown that expression (8a) remains unchanged and thus the optimal regional responses to a given $(f, k)$ regime in expression (13) and (13') continue to hold. The usual simulations are used to identify the optimal grant-distribution scheme. Figure 5 and 6 show $\left(f^{*}, k^{*}\right)$ and $\left(\lambda^{*}, \alpha^{*}\right), X^{*} / X_{0}$ and $X_{K} / X_{N-K}$ for a threshold value of $\lambda^{\max }=0.05$ and the classical utilitarian welfare function. Once $\lambda^{\max }$ applies, we observe a somewhat higher value for $f^{*}$ and a much lower value for $k^{*}$. For the modified welfare function, the threshold is much more restrictive because the optimal grant-distribution schemes apply low values of $k^{*}$ and thus produce a higher $\lambda^{*}{ }^{4}$ Overall welfare is higher than under unrestricted grant-seeking. 
Figure 5: Simulation results for the variations in $a$ (task-wide concessions, $\left.\lambda^{\max }=0.05\right)$
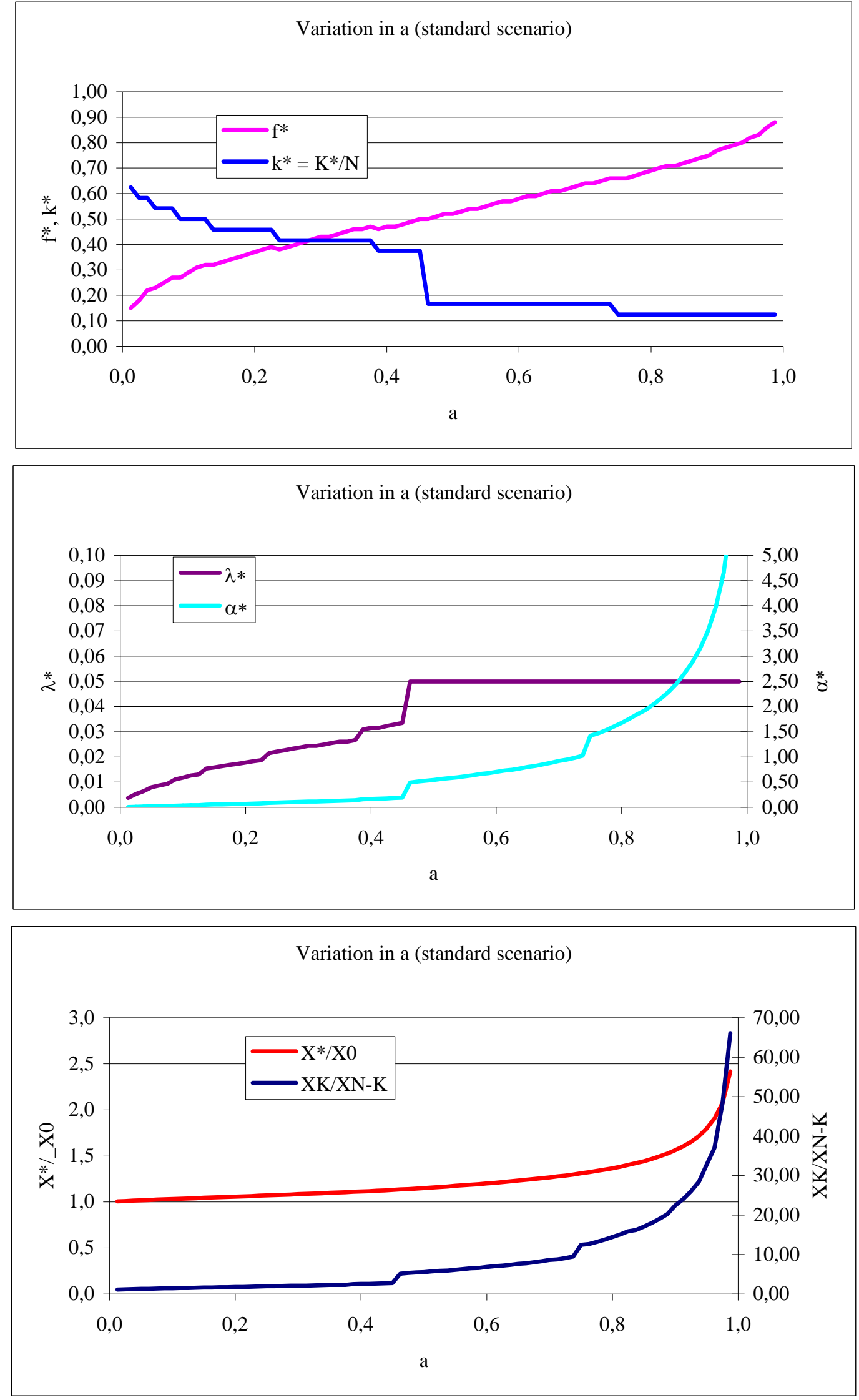
Figure 6: Simulation results for variations in a (project-specific concessions, $\lambda^{\max }=0.05$ )
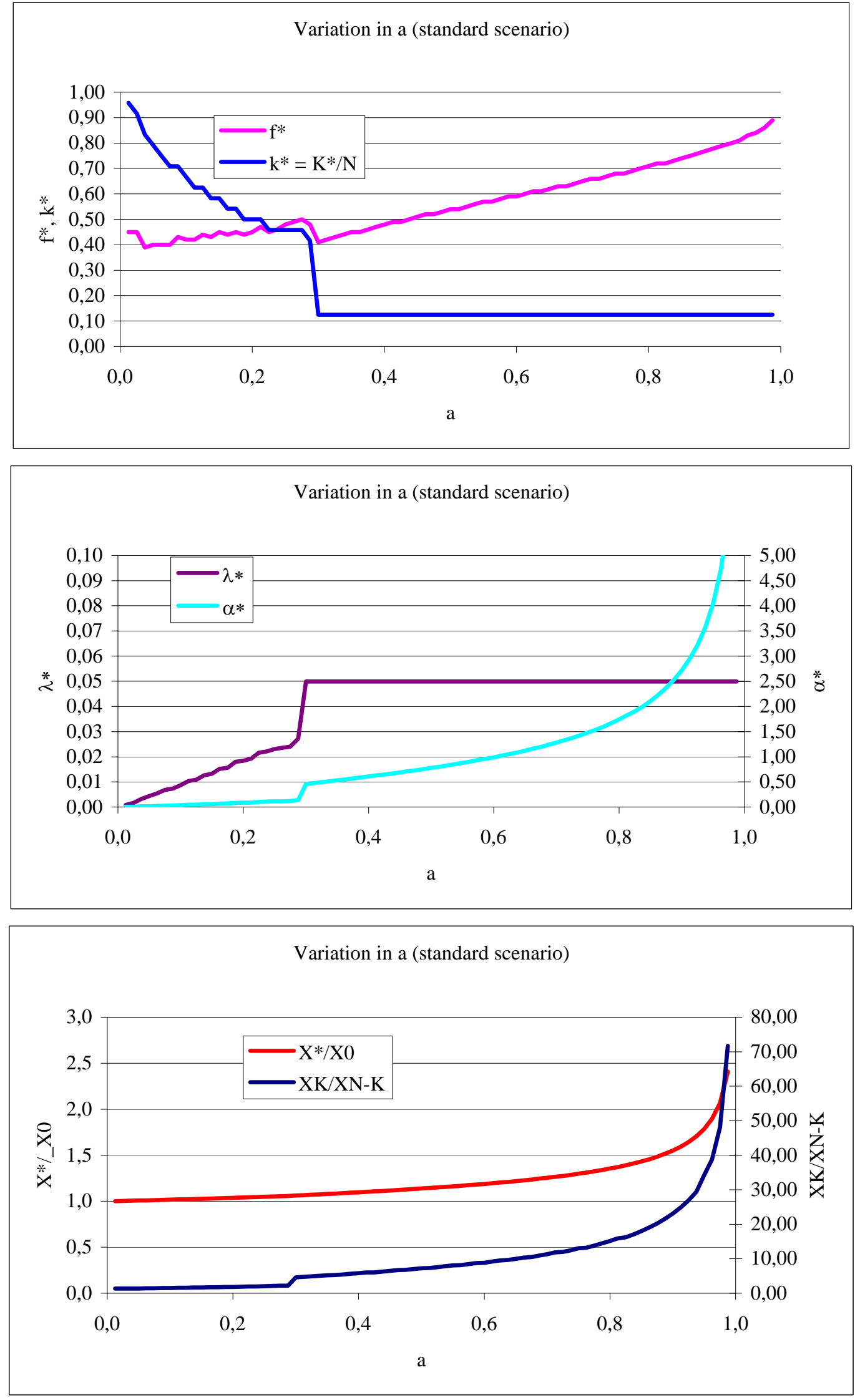


\section{Discussion}

The sections above show that conditional grants may be a suitable means of fighting government failure on the subordinate level. The optimal grant-distribution scheme is determined by the preferences of the regional authorities (described by $A_{i}^{o}, a$ ) the number of regions $N$, the regional production function (described by $q$ ) and the total funds $\bar{F}$. Under the classical utilitarian welfare function, the optimal share of conditional funds $f^{*}$ is strictly positive. It is larger, the larger the degree of government failure, the more budget seeking the regional government, the smaller the number of regions involved and the more funds are available in total. In addition, $f^{*}$ is larger under project-specific than under task-wide concessions. However, when distributional concerns are accounted for, the optimal grant-distribution scheme either contains a very small share of conditional grants or no conditional grants at all. Here, project-specific concessions lead to lower conditional grants. Apart from that, the general relationship between $f^{*}$ and the other variables is preserved. With respect to the share of recipients $k^{*}$, our simulations reveal an interesting pattern: For the standard utilitarian welfare function, we found the larger the optimal share of conditional grants, the lower the optimal share of regions that finally receive grants. At the same time, a concentration of conditional funds on a very small share of recipients is never optimal. Under the modified utilitarian welfare function, however, the optimal grant-distribution scheme concentrates a limited amount of conditional grants to a very small group of recipients. This keeps up the region's willingness to apply more adequate policy vector, albeit at the price of higher welfare losses from grant-seeking.

The applicability of conditional grants depends on a number of preconditions (e.g., Chernick, 1979; Ferris and Winkler, 1991). First, the central government must be able to identify high-quality projects before these have been implemented. In many cases, this is done by 
checking whether the potential grantees follow certain organisational and technological standards of production. Second, the granting institutions must be able to control that the standards are followed once the grantee received the funds. Third, there must be implicit or explicit sanctions for those grantees that do not follow the standards proposed in the application or provide a lower quality of goods and services. In many case, the threat to be banned from future competitions for grants is a very effective instrument to ensure compliance. Preconditions 2 and 3 are not met if the distribution of information between regional and central government is highly asymmetric. In this case, opportunistic regional governments can apply $A_{i}^{o}$ regardless of the policy vector initially stated in the application without having to fear sanctions (e.g., Boadway et al., 1999; Gilbert and Rocaboy, 2004). Consequently, conditional grants do not have any impact on the policy vector used. Given that they nevertheless evoke wasteful grant-seeking, the welfare effects of conditional grants are negative.

The fourth precondition states that there is not alternative instrument that fights government failure and reaches the same efficiency in output at lower administrative costs. In many cases, performance-based ex post grants are a suitable alternative. These funds are not granted upon application ex ante but are transferred ex post to regions that provide their public with adequate and high-quality services (e.g., Oates, 1999; Crain and O-Roark, 2004). The granting central government does not have to supervise the standards of production because it is in the own interest of the regions to apply adequate policy solutions. The granting institution can restrict itself to measuring the output. More importantly, the incentives to apply more adequate policy solutions exist for all potential recipients because these increase the output and thus the chance of receiving additional funds later. In the case of conditional grants distributed ex ante, the efficiency gains are restricted to those institutions that receive grants. If reliable and manipulation-proof measures are available, ex post grants will incur lower administrative costs. However, they bear the danger of the proxies used to measure quality become 
goals and this biases production towards applying inefficient solutions (e.g., Frey and Osterloh, 2006; Langford et al., 2006). If the necessary measures are not available or of limited quality, it is difficult to select the best-performing regions ex post. The selection procedure becomes vague and intransparent and the councils or bureaus that make the selection are subject to grant-seeking by regions as in the case of conditional grants. In this case, performancebased ex post grants do not lower administrative costs. Regardless of possible advantages in administrative costs, ex post grants are only suitable substitutes for conditional grants if two preconditions apply: First, the grantee must have sufficient funds to provide advance finance even at the risk of not receiving ex post grants. Second, the ex post grants must follow the production in due time to ensure that the agents who choose the policy solutions can expect to benefit from ex post grants. If the time horizon does not reach this far and the funds are expected for a time in which the relevant officials do not expect to be in office any more, ex post grants do not provide the desired incentives. In the extreme case, they may even provide a disincentive to apply adequate policy solutions. Applying the argument of Tabellini and Alesina (1990) on the strategic use of public deficits to the current problem, a certain government may deliberately apply inadequate solutions if re-election is unlikely. The aim is to reduce its successor's chance of receiving ex post funds (e.g., Persson and Svensson, 1989).

Given that welfare-improving effect of limiting the social costs of grant-seeking, the following question becomes immanent: Is it possible to limit grant-seeking expenditures through institutional rules? With respect to the mere costs of preparing applications, the central government may well limit the effort, e.g. by limiting the length of the application to a few pages and limit the number of applications per region. However, if the projects are complex, limiting application length makes it more difficult to judge the quality of the proposed project. Moreover, the application is not the only effort-consuming activity. In addition, regions may invest in public relations to improve their image or exert public pressure on the 
central government to press them for grants (e.g., Tullock, 1993). These activities are beyond the control of the central government and thus are very difficult to restrict unless it can credibly commit to ignore them. A credible commitment may be possible if the selection procedure is double-blind or outsourced to a neutral institution or by introducing. Another effective way to limit wasteful grant-seeking is to install an administration fee for every application. While it leaves the total grant-seeking expenditures $\lambda^{*}$ unaltered, it can restrict the degree to which they represent social waste.

The fifth condition for the applicability of conditional funds refers to the central government's motivation. In the previous sections, we assumed the central government to be welfare-maximizing. That is, it is interested in the best achievable results on the regional level and takes grant-seeking as necessary costs of introducing efficiency gains. If, however, the central government is interested in extracting rents (e.g. McChesney, 1997; Page, 2005), it will set $f>f^{*}$ and $k<k^{*}$. If rent-extraction is the only aim, $f$ finds its limit only in expression (15). In the standard scenario, the rent-maximizing combination is given by $f=0.6, K=1$. Under task-wide concessions, the corresponding concessions $(\alpha=2.19)$ are much larger than for $\left(f^{*}, k^{*}\right)$ but the welfare gains are restricted to one winning region while all $N$ regions incur grant-seeking costs of $\lambda=0.389$. The welfare losses compared to a situation without conditional grants are massive $\left(X / X_{0}=0.642\right)^{5}$

The general question of how to design an optimal grant-distribution scheme under regional government failure applies to many policy fields. Generally speaking, it applies to all situations in which a) the grantor cannot control the subordinate production directly through 
orders because the subordinate level is independent in its choice of policy solutions and b) ex post performance based grants are not applicable. In Germany, they apply to the system of financing construction facilities in higher education institutions (so-called Hochschulbau) assuming that there is incentives for the regional authorities to favour an inefficient regional or between-disciplines allocation of funds. While regional governments control the state institutions of higher education and incur all running costs, the federal government provides the means of constructing the necessary facilities. Until 2007, the share of conditional grants distributed upon application was $100 \%{ }^{6}$ The sum of funds applied for regularly exceeded the available funds and thus projects were turned down or the conditional grants was lower than the sum applied for and regions were demanded to fill in the gap. In the federalist reform of 2006/2007, the system was changed. Currently, about two thirds of the funds are given as block grants and one third is granted upon application (e.g., Sachverständigenrat, 2006: 341342). This step can be expected to reduce the regional grant-seeking effort substantially.

A mix of conditional and block grants is often used for the services provided are funded publicly but carried out by non-governmental organisations, e.g. church-based institutions that are active in the field of social welfare. Here, the carriers are free in their choice of policy solutions and possible inefficiencies may arise from their (ideologically co-determined) policy preferences and from the self-interest of their employees. In Germany, youth welfare policies provide an example for this. Here, the regions are in formally responsible but the relevant services are provided on the local level - a substantial part by religious and other non-profit organisations. Unlike in the "Hochschulbau", the share of conditional grants was initially lower but has been increased considerably in recent years. This change follows the introduc- 
tion of New Public Management in the German regions and an increasing importance of quality management within the non-profit organisations (e.g., Gresse, 1998). Given that distributional concerns may be very important in this field, the theory provides a note of caution concerning conditional grants. They are only justified if efficiency gains induced by the competition for funds are substantial. In any case, substantial means are diverted to grant-seeking. Additional costs may result from the fact that conditional grants require evaluations. These bear the danger of crowding out the intrinsic motivation (e.g. Frey and Osterloh, 2006) especially among the employees in the non-profit organisations. An empirical analysis of the impact of conditional grants on motivation and output in the field of youth welfare programs might be an interesting albeit challenging endeavour.

\section{Conclusion}

This paper addresses the welfare-effects of conditional vertical grants when regions are subject to government failure. Conditional grants can improve the efficiency of public production but they also evoke wasteful grant-seeking. We use a three-step game-theoretic framework to derive the welfare-maximizing grant-distribution scheme for the central government. This optimal scheme involves some share of funds to be distributed as conditional grants regardless of the regional characteristics if the government aims at maximizing a standard utilitarian welfare function. Conditional grants are effective and thus should be used intensively if the regional government are budget-maximizers with loose policy-preferences. In order to induce substantial changes in the policy vectors among the recipient regions and at the same time restrict grant-seeking expenditures, conditional funds must be distributed among a moderate share of regions. Concentrating funds to a very small group of recipients is never optimal. This result does not hold for the case when distributional concerns are of importance. Here, corner solutions without conditional grants are optimal in a large number of cases. 
Whenever conditional grants remain welfare-enhancing, they should be small in size and concentrated to a small number of recipients.

Conditional grants must be considered in situations where a) the potential recipients are free in their choice of policy solutions and policy changes can only be achieved by appropriate incentives and b) the requirements to apply ex post performance based grants are not met. Especially in the field of complex, long-term projects, the latter do not represent a true alternative to conditional grants. Here, the government must rely on setting incentives for regions to apply policy solutions that meet certain standards. In order to restrict the costs of grantseeking, it can set an application fee or make a binding commitment to make grant-seeking expenditures that go beyond the necessary costs of preparing the application ineffective.

\section{References}

Austen-Smith, D. (1997). Interest groups: Money, information and influence. in: Mueller (ed.): 296-321.

Belleflamme, P. and Hindriks, J. (2005). Yardstick competition and political agency problems. Social Choice and Welfare 24: 155-169.

Berry, S. K. (1993). Rent-seeking with multiple winners. Public Choice 77: 437-443.

Bischoff, I. (2008). Mentale Modelle, Lernen und ihr Beitrag zur Modellierung des politischen Wettbewerbs in einer komplexen Welt. Neuropsychoeconomics 3: 3-19.

Boadway, R. Horiba, I. and Raghbendra, J. (1999). The provision of public services by government funded decentralized agencies. Public Choice 100: 157-184. 
Buchanan, J. M. et al. (1980, eds). Towards a theory of the rent-seeking society. College station: Texa A\&M University Press.

Byrnes, J. and Dollery, B. (2002). Local government failure in Australia? An empirical Analysis of New South Wales. Australian Journal of Public Administration 61(3): 54-64.

Chang, C. and Turnbull, G, K. (2002). Bureaucratic behavior in the local public sector: A revealed preference approach. Public Choice 113: 191-209.

Chernick, H. A. (1979). An economic model of the distribution of project grants. in: Mieszkowski, P. and Oakland, W. H. (eds). Fiscal federalism and grants-in-aid. Washington, D.C: The Urban Institute: 81-103.

Crain, W. M. and O-Roark, J. B. (2004). The impact of performance-based budgeting on state fiscal performance. Economics of Governance 5: 167-186.

Fenge, R. and Wrede, M. (2007). EU financing and regional policy: Vertical fiscal externalities when capital is mobile. Finanzarchiv 63:457-476.

Ferris, J. M. and Winkler, D. R. (1991). Agency theory and intergovernmental relationships. Prud'homme, R. (ed.). Public finance with several levels of government. The Hague: Foundation Journal Public Finance: 155-166.

Flynn, N. (2007). Public Sector Management, $5^{\text {th }}$ edition. London etc: Sage Publications.

Frey, B. S. and Osterloh, M. (2006). Evaluations: Hidden information, questionable beliefs, and superior alternatives. Institute for Empirical Research in Economics University of Zurich Working Paper No. 302. 
Greese, D. (1998). Kommunale Kinder- und Jugendpolitik. in: Wollmann, H. and Roth, R. (eds): Kommunalpolitik. Politisches Handeln in den Gemeinden. Opladen: Leske + Budrich: 717-731.

Gilbert, G. and Rocaboy, Y. (2004). The central government grant allocation problem in the presence of misrepresentation and cheating. Economics of Governance 5: 137147.

Grossman, P. J. (1994). A political theory of intergovernmental grants. Public Choice 78: 295-303.

Grossman, P. J. (1996). The distribution of Federal grants in aid: the increasing importance of PACs relative to state and local political parties. Applied Economics 28: 975984.

Grossman, P. J., Mavros, P. and Wassmer, R. E. (1999). Public sector technical inefficiencies in large US cities. Journal of Urban Economics 46: 278-299.

Hoy. M. et al. (2001). Mathematics for Economics. $2^{\text {nd }}$ edition. Cambridge, Mass.: MIT Press.

Langford, C. H. et al. (2006). Indicators and outcomes of Canadian university research: Proxies becoming goals? Research policy 35: 1586-1598.

McChesney, F. S. (1997). Money for nothing: Politicians, rent extraction and political extortion, Cambridge and London: Harvard University Press.

Mueller. D. C. (1997, ed). Perspectives on public choice. Cambridge: Cambridge University Press.

Niskanen, W. A. (1971). Bureaucracy and representative government. Chicago: AldineAltherton. 
Oates, W. E. (2005). Towards a second generation theory of fiscal federalism. International Tax and Public Finance 12: 349-373.

Oates, Wallace E. (1999). An essay on fiscal federalism. Journal of Economic Literature 37: 1120-1149.

Page, S. (2005). What's new about the New Public Management? Administrative change in human services. Public Administration Review 65: 713-27.

Persson, T. and Svensson, L. E. O. (1989). Why a stubborn conservative would run a deficit: Policy with time-inconsistent preferences. Quarterly Journal of Economics 104: 325-345.

Romer, D. (2003). Misconceptions and political outcomes. The Economic Journal 113:1-20.

Shah, A. (2006). A practitioner's guide to intergovernmental fiscal transfers. World Bank Policy Research Working Papers 4039.

Tabellini, G. and Alesina, A. (1990). Voting on the budget deficit. American Economic Review 80: 37-49.

Tullock, G. (1980). The costs of transfers. in: Buchanan et al. (eds): 269-282.

Tullock, G. (1993). Rent Seeking. Cambridge: Cambridge University Press.

Wintrobe, R. (1997). Modern bureaucratic theory. in: Mueller (ed.): 373-390.

Worthington, A. C. and Dollery, B. E. (1998). The political determination of intergovernmental grants in Australia. Public Choice 94: 299-315. 


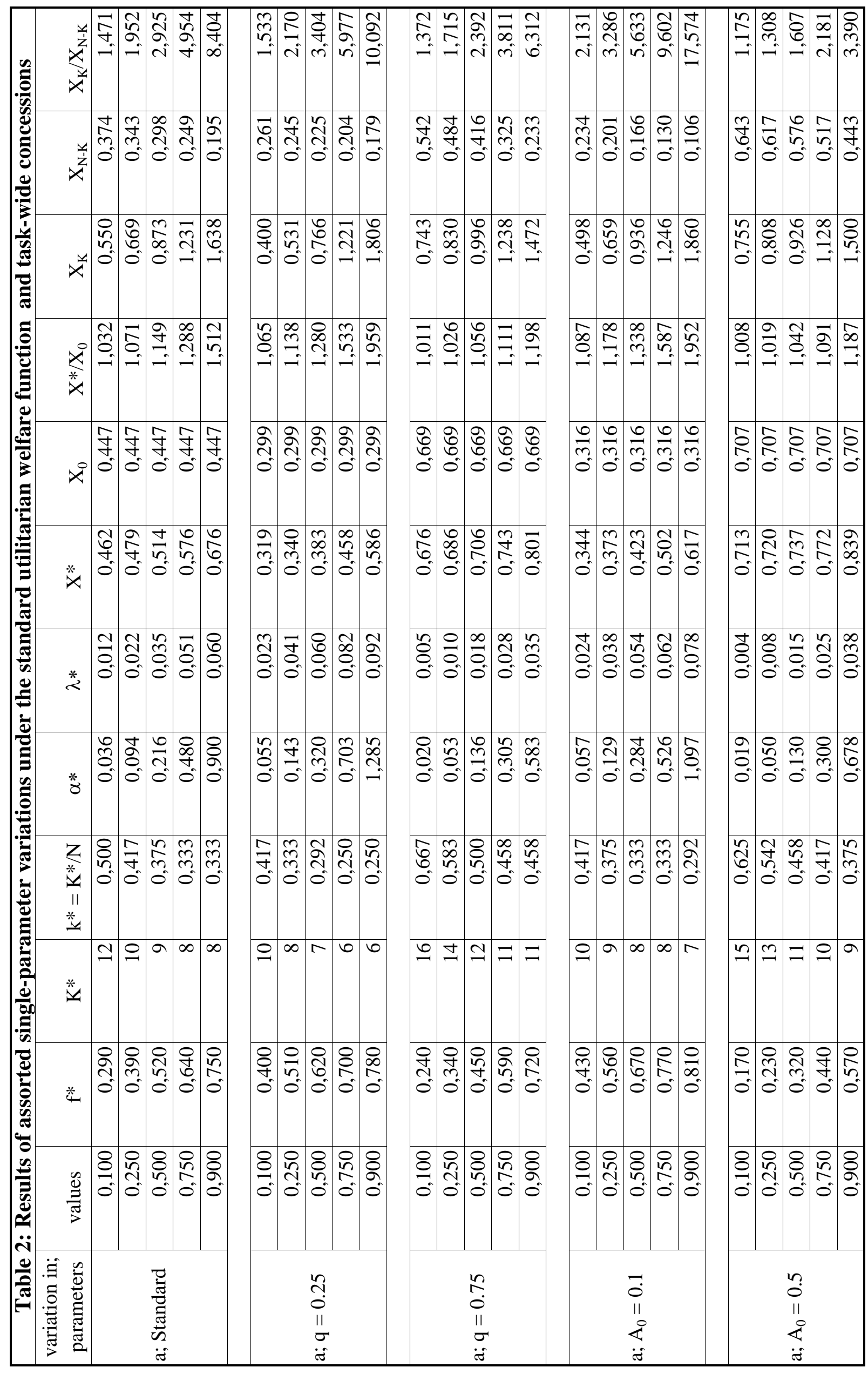




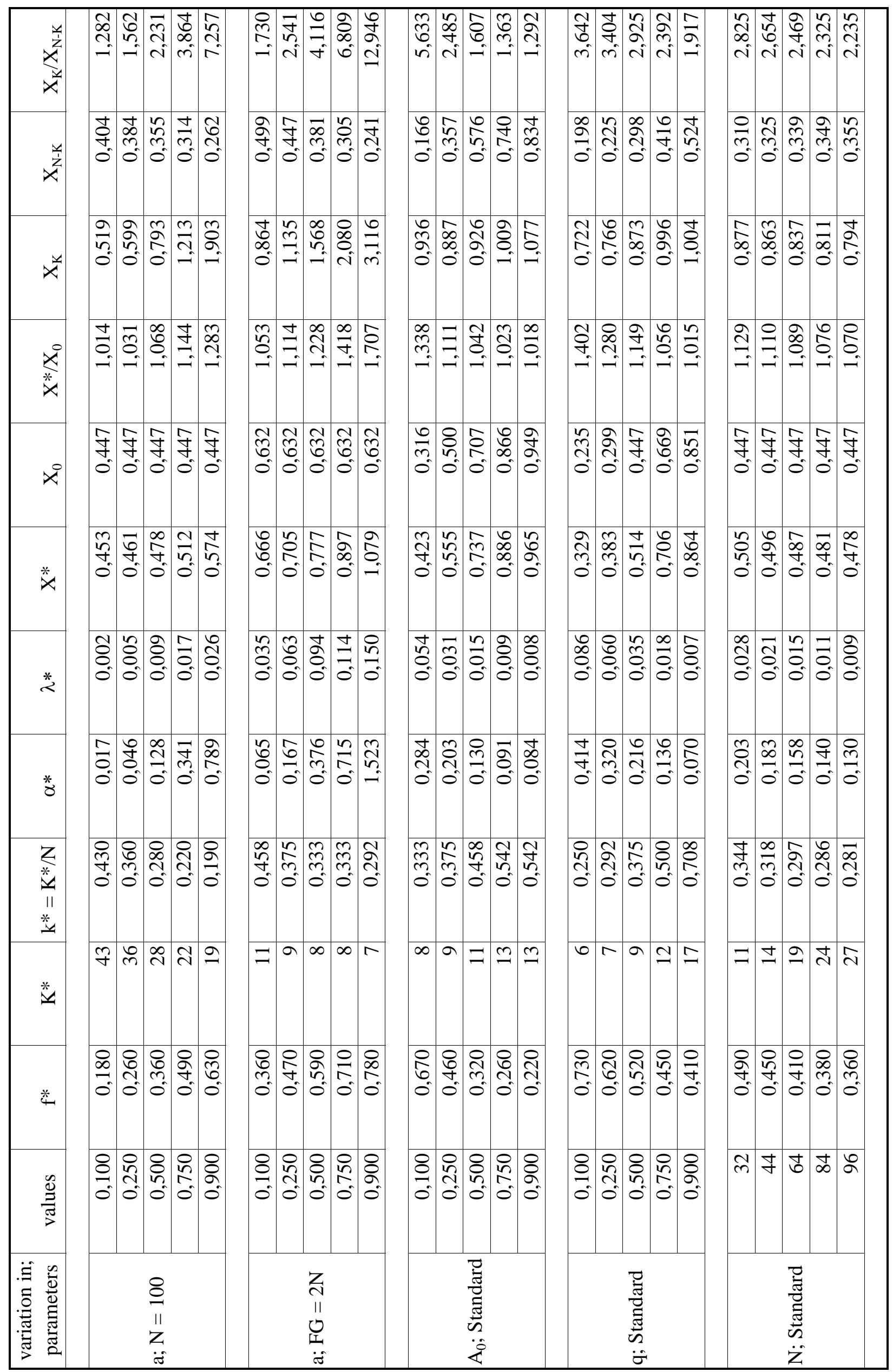




\begin{tabular}{|c|c|c|c|c|c|c|c|c|c|c|}
\hline$\underbrace{\frac{y}{x}}_{x}$ & 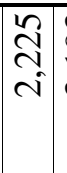 & $\begin{array}{l}m \\
\tilde{\sigma} \\
\vec{m}\end{array}$ & 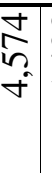 & 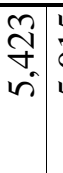 & $\begin{array}{l}n \\
\sigma \\
\omega \\
\omega\end{array}$ & $\begin{array}{l}0 \\
\tilde{D} \\
\stackrel{2}{v} \\
v\end{array}$ & $\begin{array}{c}\mathbf{t} \\
\text { - } \\
\text { in }\end{array}$ & 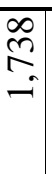 & & 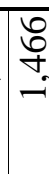 \\
\hline$x_{x}^{\frac{y}{z}}$ & 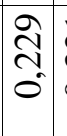 & $\begin{array}{c}\vec{ন} \\
\tilde{2} \\
\sigma^{\prime}\end{array}$ & $\begin{array}{l}0 \\
0 \\
\vdots \\
0 \\
0\end{array}$ & $\begin{array}{l}t \\
t \\
t \\
0\end{array}$ & 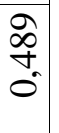 & 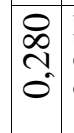 & $\begin{array}{l}\mathrm{L} \\
\stackrel{1}{0} \\
\\
0\end{array}$ & $\begin{array}{l}\mathscr{L} \\
\text { Ṅ } \\
0\end{array}$ & & $\frac{d}{0}$ \\
\hline$x$ & $\mid \begin{array}{c}0 \\
\text { Lิ } \\
0 \\
0\end{array}$ & $\begin{array}{l}\mathscr{D} \\
\stackrel{1}{ } \\
\stackrel{-}{-1}\end{array}$ & 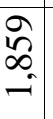 & $\begin{array}{c}\stackrel{\sim}{\mathrm{D}} \\
\sim \\
\sim\end{array}$ & 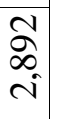 & 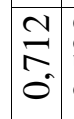 & $\begin{array}{l}\infty \\
\text { Nิ } \\
\text { م̂ } \\
0\end{array}$ & $\begin{array}{l}\text { Oे } \\
\text { m. } \\
\sigma^{2}\end{array}$ & $\begin{array}{l}\vec{\nabla} \\
\vec{m} \\
0^{2}\end{array}$ & 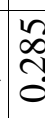 \\
\hline$\frac{x^{0}}{*}$ & 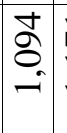 & 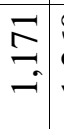 & 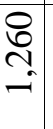 & $\begin{array}{l}\mathscr{D} \\
\underset{\sim}{m} \\
\sim \\
-1\end{array}$ & 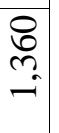 & $\begin{array}{l}\hat{0} \\
-1 \\
-1\end{array}$ & $\begin{array}{l}\mathcal{N} \\
\hat{O} \\
-1\end{array}$ & $\underset{-}{\stackrel{f}{J}}$ & $\overline{\tilde{m}}$ & a \\
\hline$x^{0}$ & \begin{tabular}{|c|}
0 \\
$\bar{m}$ \\
0 \\
0
\end{tabular} & $\begin{array}{l}8 \\
8 \\
10 \\
0\end{array}$ & $\begin{array}{l}\hat{2} \\
\hat{0}\end{array}$ & \begin{tabular}{c|c}
0 \\
$\mathscr{D}$ \\
$\infty$ \\
0 \\
0
\end{tabular} & $\begin{array}{l}g \\
\sigma \\
0\end{array}$ & \begin{tabular}{|c|} 
\\
$\infty$ \\
$m$ \\
$\tilde{o}^{\prime}$
\end{tabular} & $\begin{array}{l}\stackrel{p}{m} \\
m \\
0^{\prime}\end{array}$ & $\begin{array}{l}\underset{\Delta}{\Delta} \\
\text { O }\end{array}$ & 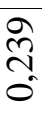 & $\underset{\mathbb{N}}{\mathbb{J}}$ \\
\hline$\stackrel{*}{x}$ & 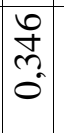 & $\begin{array}{l}\mathscr{D} \\
\mathbb{D} \\
\stackrel{1}{2} \\
0\end{array}$ & $\begin{array}{l}-1 \\
\infty \\
0 \\
0\end{array}$ & $\begin{array}{l}\stackrel{\infty}{+} \\
\stackrel{\sim}{-} \\
\rightarrow\end{array}$ & 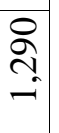 & \begin{tabular}{l}
$\mathscr{\mathscr { T }}$ \\
\multirow{T}{}{} \\
$0^{\prime}$
\end{tabular} & $\begin{array}{l}\text { 岗 } \\
\text { m. } \\
0\end{array}$ & 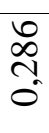 & & 胥 \\
\hline$\stackrel{*}{2}$ & $\begin{array}{c}m \\
\tilde{\sigma} \\
0 \\
0\end{array}$ & $\begin{array}{l}0 \\
0 \\
0 \\
0 \\
0\end{array}$ & $\begin{array}{l}\stackrel{ \pm}{\sim} \\
\underset{0}{0}\end{array}$ & \begin{tabular}{|l|}
$\infty$ \\
$a$ \\
- \\
0 \\
0
\end{tabular} & $\begin{array}{l}\stackrel{\sim}{\checkmark} \\
\stackrel{\sim}{\sim} \\
0\end{array}$ & $\mid \begin{array}{c}\stackrel{D}{2} \\
0 \\
0 \\
0\end{array}$ & 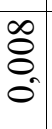 & $\begin{array}{l}m \\
8 \\
0 \\
0\end{array}$ & $\overline{8}$ & $\bar{\Xi}$ \\
\hline *ै & \begin{tabular}{c}
$\stackrel{I}{\sim}$ \\
\hdashline \\
0
\end{tabular} & \begin{tabular}{|c|} 
\\
$\stackrel{1}{\sim}$ \\
0 \\
0
\end{tabular} & $\begin{array}{l}\vec{y} \\
\dot{\sigma} \\
\sigma^{\prime}\end{array}$ & 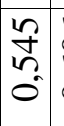 & $\begin{array}{l}0 \\
0 \\
0 \\
0\end{array}$ & $\mid \begin{array}{c}9 \\
0 \\
-1 \\
0\end{array}$ & $\begin{array}{l}\hat{0} \\
\hat{0}\end{array}$ & $\begin{array}{l}\hat{\theta} \\
\mathscr{0} \\
0\end{array}$ & $\begin{array}{l}\text { ? } \\
\text { O } \\
0\end{array}$ & $\begin{array}{l}0 \\
0 \\
0 \\
0\end{array}$ \\
\hline 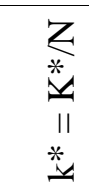 & $\begin{array}{l}\vec{\gamma} \\
\sigma^{\prime}\end{array}$ & $\mid \begin{array}{l}\mid N \\
\hat{N} \\
\tilde{o}^{2}\end{array}$ & $\begin{array}{l}m \\
m \\
m \\
0\end{array}$ & $\mid$ & $\begin{array}{l}m \\
m \\
m \\
0\end{array}$ & $\begin{array}{l} \\
\text { m. } \\
\sigma^{\prime}\end{array}$ & 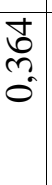 & 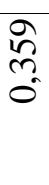 & & 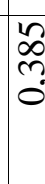 \\
\hline$\stackrel{\text { 艺 }}{\stackrel{2}{*}}$ & $\stackrel{0}{\circ}$ & $a$ & $\infty$ & $\infty$ & $\infty$ & $\exists$ & 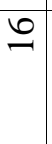 & $\tilde{N}$ & $\tilde{\tilde{}}$ & $\hat{\mathrm{m}}$ \\
\hline$\underbrace{*}_{4}$ & 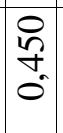 & \begin{tabular}{|c|} 
\\
员 \\
웅
\end{tabular} & 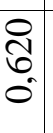 & $\mid \begin{array}{l}0 \\
0 \\
0 \\
0 \\
0\end{array}$ & $\begin{array}{l}8 \\
\& \\
0 \\
0\end{array}$ & \begin{tabular}{|l|} 
\\
$\stackrel{1}{+}$ \\
$\sigma^{\prime}$ \\
\end{tabular} & $\begin{array}{l}\stackrel{8}{2} \\
\text { m. } \\
0\end{array}$ & $\begin{array}{l}0 \\
\text { mे } \\
0^{\prime}\end{array}$ & & $\stackrel{\substack{\mathfrak{d} \\
0}}{0}$ \\
\hline$\frac{\mathscr{D}}{\stackrel{\pi}{J}}$ & $\underset{-1}{\simeq}$ & ஓे & 8 & ৪) & $\stackrel{\infty}{\infty}$ & $\tilde{m}$ & $\forall$ & ఫే & ১ & $\mathscr{~}$ \\
\hline 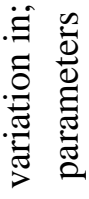 & & & $\begin{array}{l}\underset{\sim}{ \pm} \\
I 1 \\
Z \\
\ddot{1}\end{array}$ & & & & & 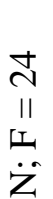 & & \\
\hline
\end{tabular}




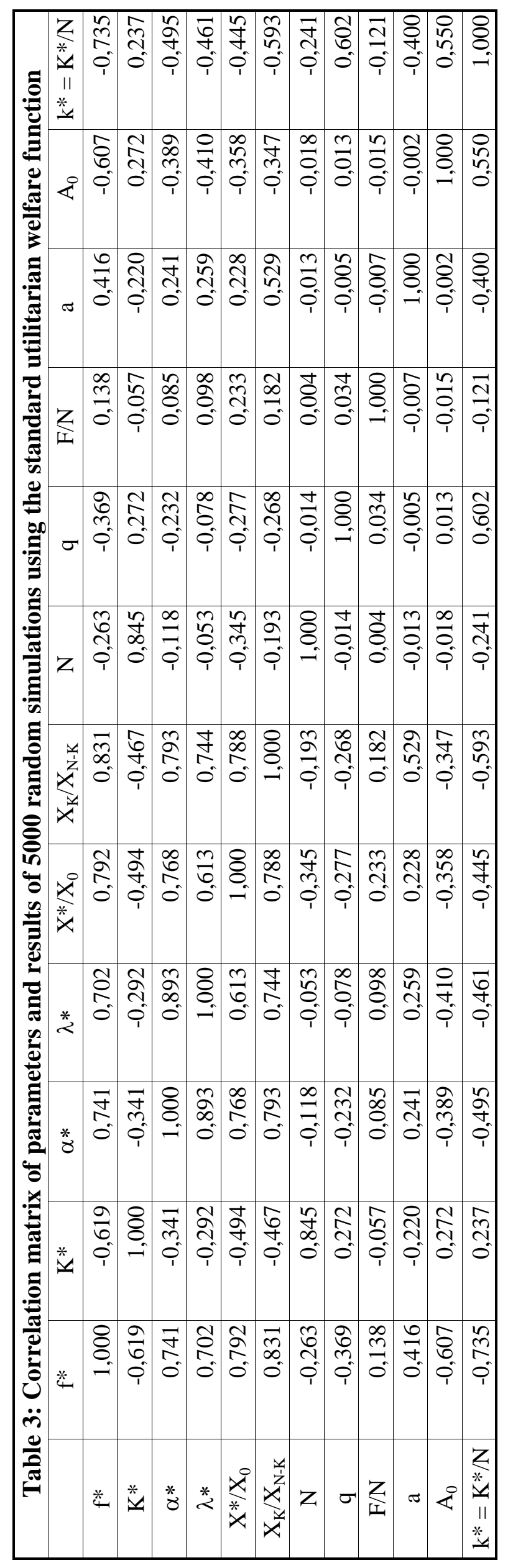




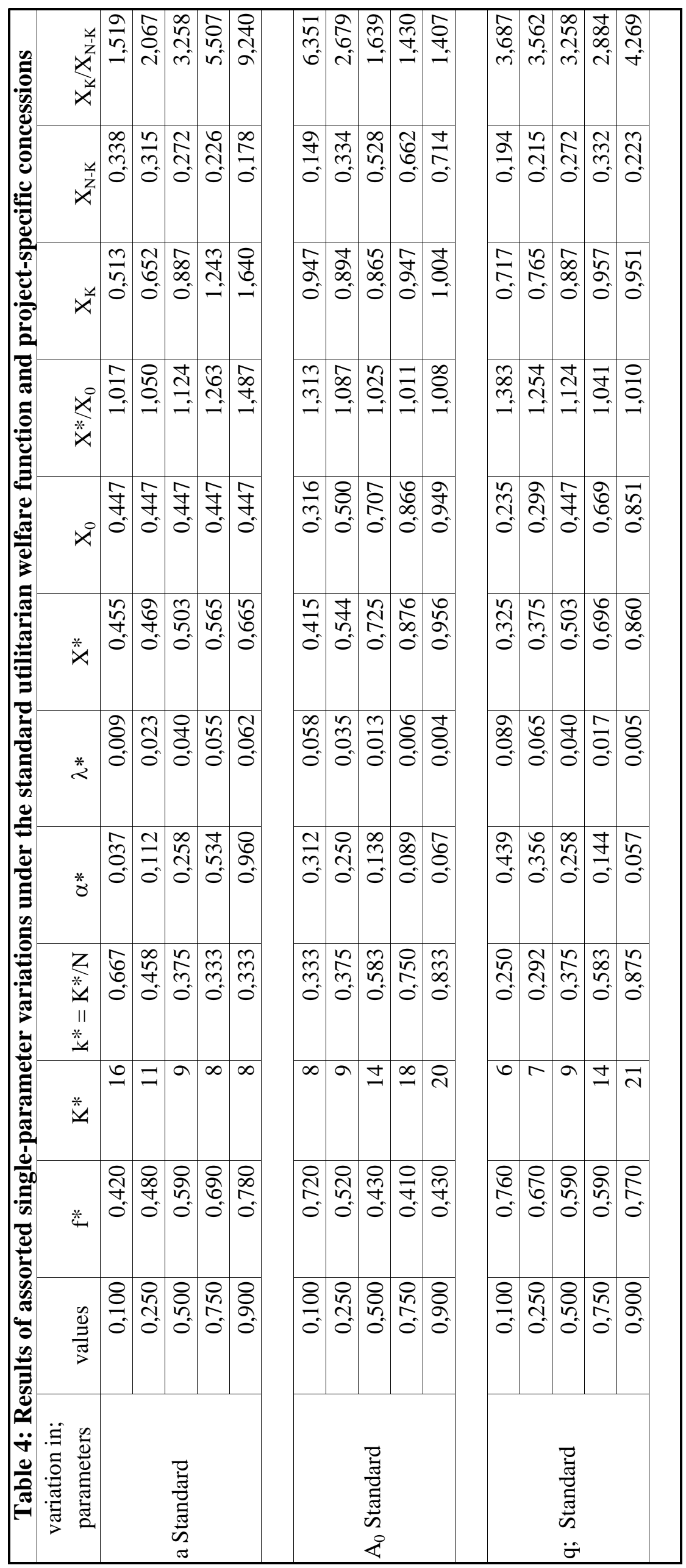




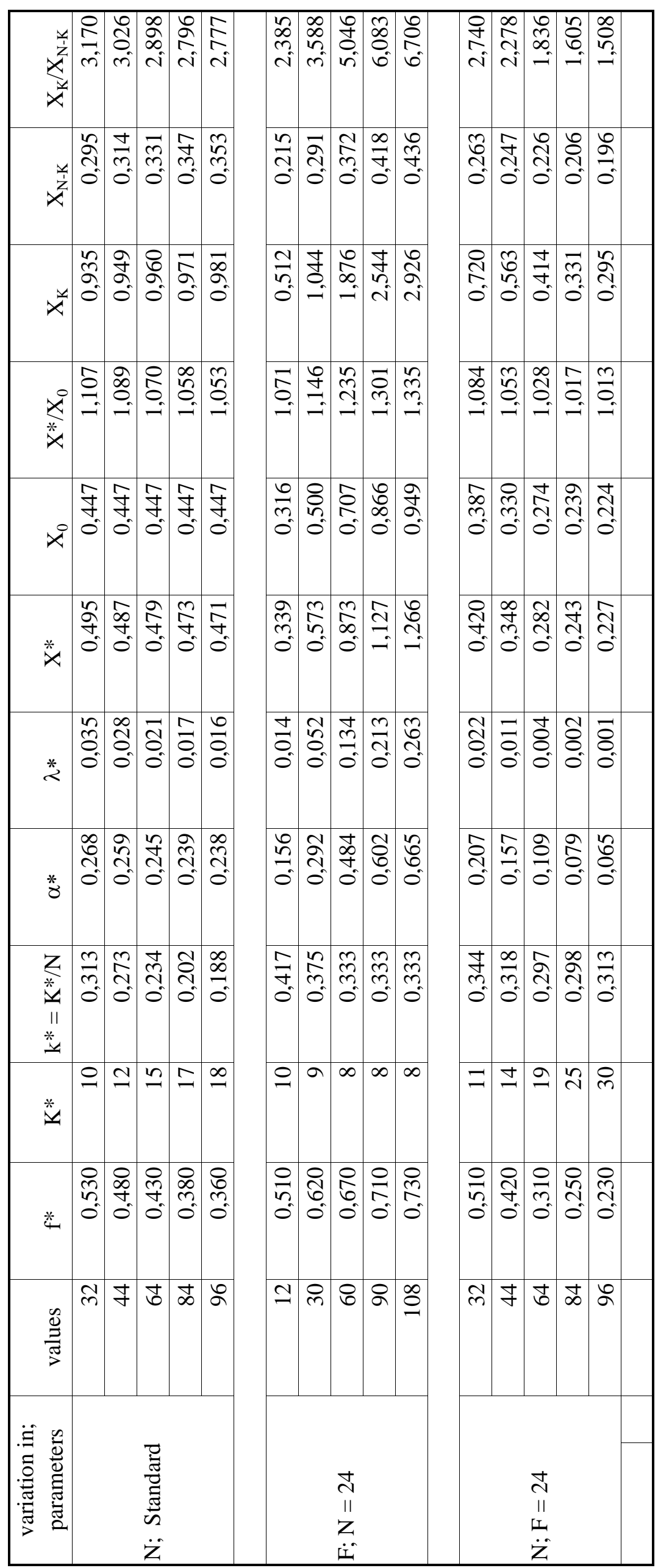




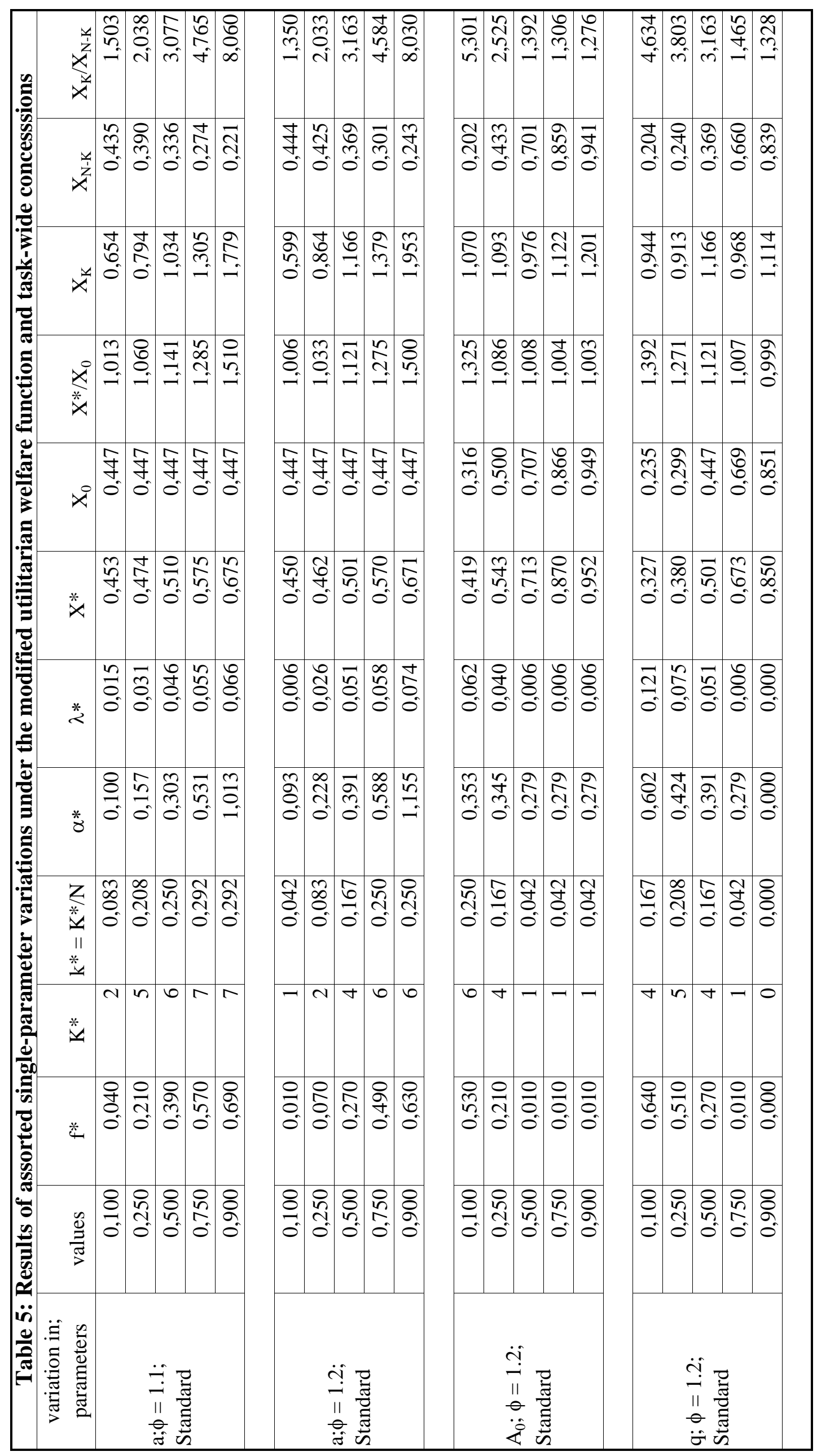




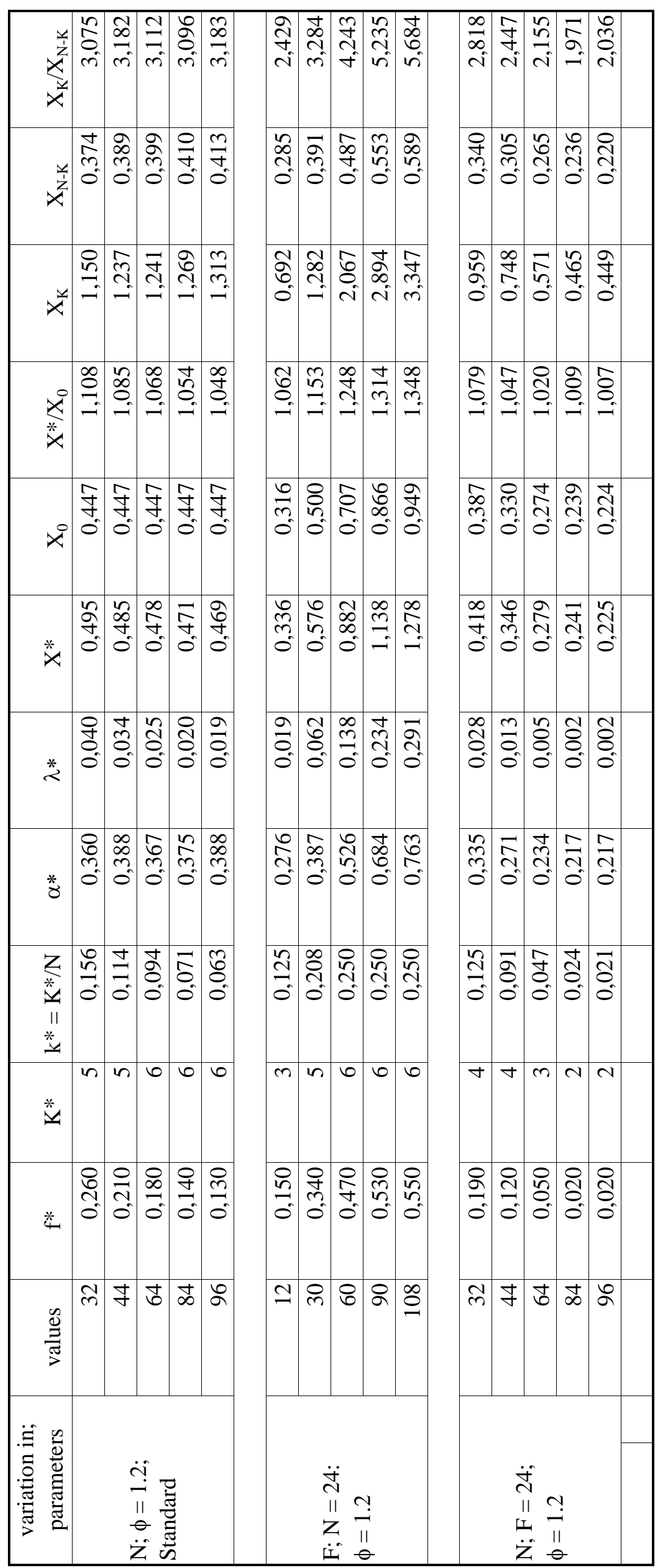




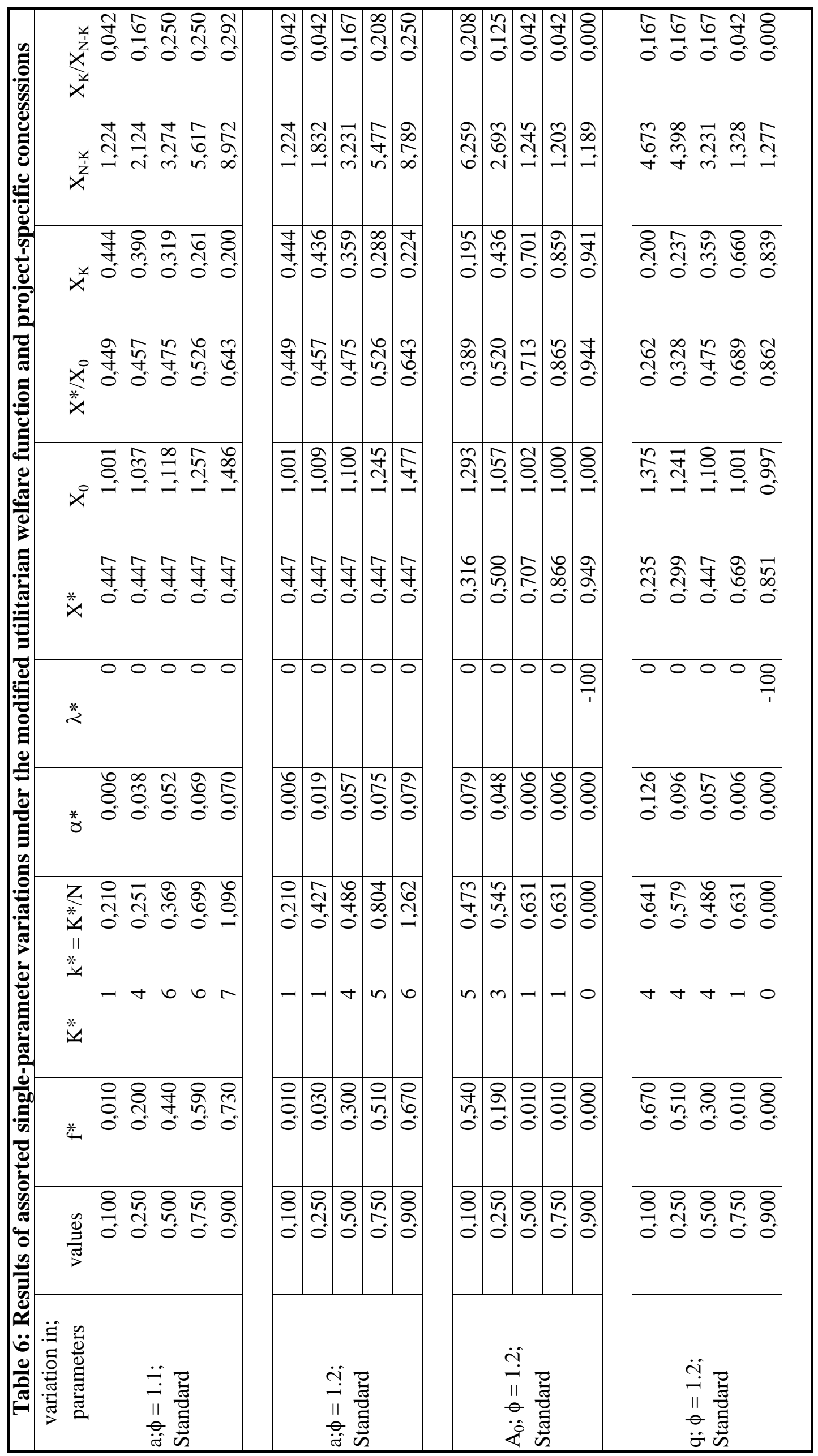




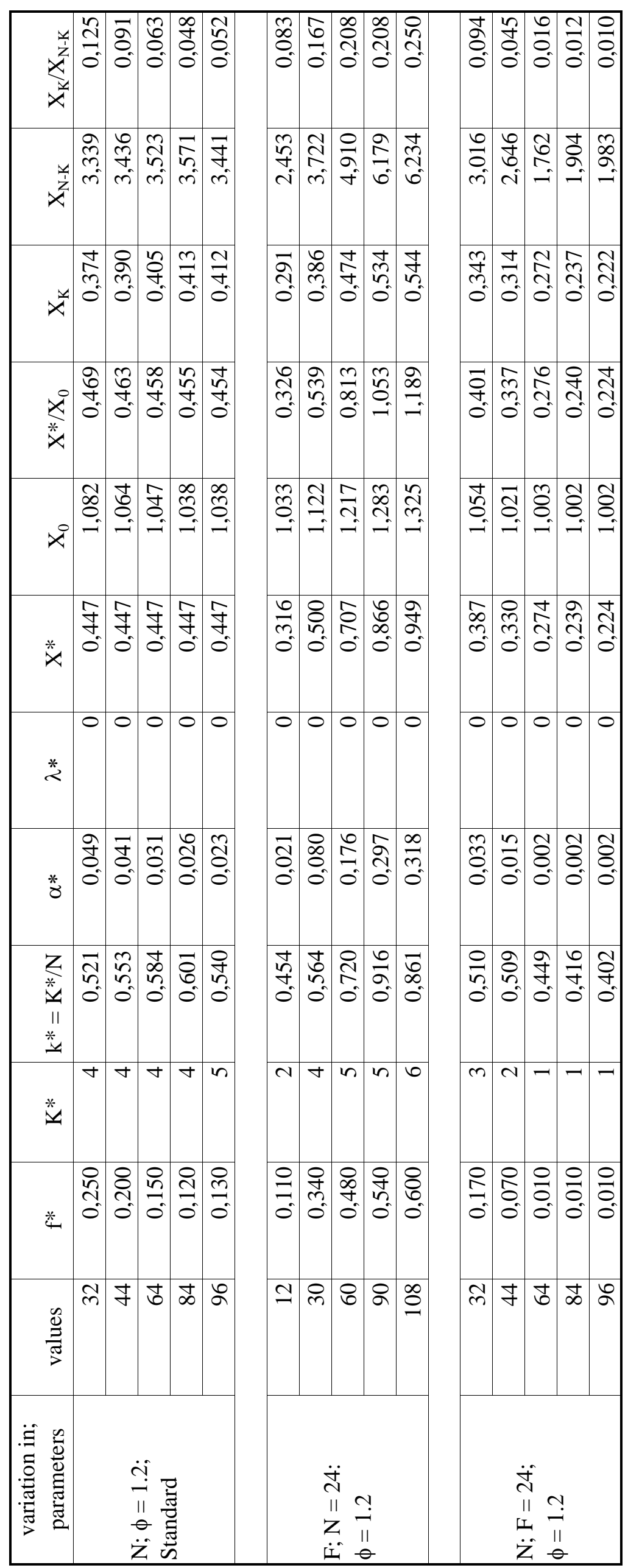

